\title{
Ultra-efficient Copper Ions Adsorption of Chitosan- montmorillonite Composite Aerogel for Wastewater Treatment
}

\section{Xin Ye}

Nanjing Tech University

\section{Sisi Shang}

Nanjing Tech University

Yifan Zhao

Nanjing Tech University

Sheng Cui ( $\nabla$ cui2002sheng@126.com )

Nanjing University of Technology

\section{Ya Zhong}

Nanjing Tech University

\section{Longjin Huang}

Nanjing Tech University

\section{Research Article}

Keywords: Chitosan, Montmorillonite, Cu2+, Aerogel, Environmental protection

Posted Date: March 1st, 2021

DOI: https://doi.org/10.21203/rs.3.rs-242683/v1

License: (c) (1) This work is licensed under a Creative Commons Attribution 4.0 International License. Read Full License 
2 montmorillonite composite aerogel for wastewater treatment

3 Xin Ye ${ }^{1,2}$, Sisi Shang ${ }^{1,2}$,Yifan $\mathrm{Zhao}^{1,2}$,Sheng Cui ${ }^{1,2^{*}}$,Ya Zhong ${ }^{1,2^{*}}$,Longjin Huang ${ }^{1,2}$

41 College of Materials Science and Engineering, Nanjing Tech University, 211800 Nanjing, China

52 Jiangsu Collaborative Innovation Center for Advanced Inorganic Function Composites, Nanjing

6 Tech University, 211800 Nanjing, China

$7 \quad$ *Corresponding Author

8 Sheng Cui

9 E-mail address: cui2002sheng@126.com

$10 \quad$ Ya Zhong

11 E-mail address: yzhong@njtech.edu.cn

\section{Abstract}

The modified montmorillonite(MMT) has a two-dimensional stable and ordered lamellar structure. The addition of chitosan(CS) cross-links the two-dimensional sheets to build a threedimensional network structure with a high specific surface area. We have prepared the best MMTbased water treatment materials that have been reported. This new type of aerogel can efficiently adsorb heavy metal ions in wastewater. The structure and performance of the composite material were characterized in this article. Besides, the adsorption kinetics, adsorption thermodynamics, $\mathrm{pH}$ influence, and recycling performance are all focused on. The adsorption equilibrium time of CSMMT2 is $50 \mathrm{~min}$. The removal rate of $\mathrm{Cu}^{2+}$ is as high as $98.21 \%$. The maximum adsorption capacity 
quasi-second-order kinetic model and the Langrangian adsorption isotherm. After three cycles, the removal rate of $\mathrm{Cu}^{2+}$ by CS-MMT2 remained above $80 \%$. This article also involves the discussion of the material's adsorption mechanism for $\mathrm{Cu}^{2+}$. This is a kind of environmentally friendly material that can be mass-produced, cheap, efficient, and excellent, which is of great significance to the development of environmental protection.

Key Words: Chitosan, Montmorillonite, $\mathrm{Cu}^{2+}$, Aerogel, Environmental protection

\section{Introduction}

With the exploitation of natural resources, the pollution of water resources has attracted much attention(Kolpin et al. 2002). In several countries and regions, it has already exceeded the selfpurification capacity of natural water bodies, causing much severe environmental pollution( $\mathrm{Fu}$ and Wang 2011). Heavy metal pollution is one of the most important parts of the water environment pollution(Jarup 2003; Zou et al. 2016). In industry and agriculture, a large number of pollutants, including heavy metals, have been discharged into rivers, which resulted in deteriorating water quality, causing a series of serious consequences(Bailey et al. 1999).

Copper is an essential trace element in the human body. It can be absorbed from various sources, such as food, dust, and water. Excess copper may lead to several symptoms such as nausea, vomiting, abdominal muscle pain. Accumulating in the liver, it may cause various diseases such as gastrointestinal discomfort, kidney, and liver damage (Thit et al. 2020). It can be fatal at extreme doses (Shabbir et al. 2020). Therefore, it is essential to remove residual copper ions in water. Numerous articles have reported various sewage treatment methods containing heavy metal ions, including adsorption, ion exchange, chemical precipitation, membrane filtration, electrochemical 
techniques, and reverse osmosis (Moja et al. 2020). Compared with others, adsorption is a simple, easy-to-operate, and inexpensive way to treat heavy metal ions (El-Kousy et al. 2020). Recent research has focused on relatively low-cost adsorbents such as zeolite(Bailey et al. 1999), montmorillonite(Uddin 2017), kaolinite clay(Yuan et al. 2015), mineral silicate(Luo et al. 2010), sepiolite(Sun et al. 2013), chitosan polymer(Wan et al. 2010), and biological packing(Wu et al. 2004), etc. For any adsorbent, the adsorption capacity is the most critical technical indicator. Especially for low-concentration heavy metal ion wastewater, the development of nano-adsorption materials has a long way to go(Liu et al. 2020b). Therefore, it is necessary to obtain a new adsorbent with high adsorption capacity, high specific surface area, rich pore structure, abundant sources, low cost, good stability, easy recovery, and regeneration.

In recent years, aerogel has been considered a promising insulation material. (Baetens et al. 2011) At the same time, high porosity and large specific surface area show superior adsorption capacity (Cui et al. 2018). It can be widely used in sewage treatment, air purification, nuclear waste treatment, and other environmental protection fields(Pierre and Pajonk 2002).

Modified clay, such as montmorillonite, is regarded as one of the best inorganic adsorbents because of its high utilization rate, friendly environment, and high negative charge, which can absorb positively charged metal ions(Mahouachi et al. 2020). Chitosan is hydrophilic, biocompatible, biodegradable, non-toxic, has high mechanical strength and film-forming properties, as well as antibacterial properties( $\mathrm{Li}$ et al. 2016). The amino $\left(-\mathrm{NH}_{2}\right)$ and hydroxyl $(-\mathrm{OH})$ groups inherent in the chemical structure of chitosan are the main functional groups that adsorb various heavy metals in water. By modifying the structure of chitosan with - $\mathrm{COOH}$ group, its solubility at $\mathrm{pH}=7$ can be increased without affecting the above properties(Wang et al. 2017). Studies have 
shown that ionic imprinted montmorillonite nanosheet/chitosan (IIMNC) gel beads provide active adsorption sites through their highly efficient cation exchange performance for the selective adsorption of $\mathrm{Cu}^{2+}(\mathrm{Q}$ in et al. 2020). The montmorillonite-chitosan composite material can provide hydrophobicity and functional groups to improve the performance of montmorillonite in wastewater treatment(Hu et al. 2017b). The interaction sequence of adsorption-related groups in the chitosanMontmorillonite composite showed that the adsorption capacity of bonding with $\mathrm{NH}_{3}{ }^{+}$may be greater than that of bonding with hydroxyl(Hu et al. 2017a). The clay-chitosan nanocomposite material is expected to achieve a major breakthrough in the treatment of heavy metal ion wastewater. Our team combined chitosan aerogel and montmorillonite designed a new high-efficiency adsorbent. Montmorillonite can be used as ideal templates for preparing nanomaterials and supporting chitosan hydrogels due to their high surface area and stable structure. We use the $\mathrm{LiOH} /$ urea dissolving system to process chitosan raw materials and the chemical precipitation method to compound Montmorillonite. By adjusting the concentration of the initial reactants, the size, pore size, and mechanical properties of the synthesized CS-MMT aerogel can be determined. CS-MMT aerogel nanocomposite can be used as an environmentally friendly adsorbent for the removal of $\mathrm{Cu}^{2+}$ from wastewater. With its outstanding performance, it will occupy a place in the field of wastewater treatment. The adsorption kinetics and adsorption thermodynamics were used to systematically study the maximum adsorption capacity. The separation and reusability of CSMMT aerogel were also studied in detail.

\section{Experimental Section}

\subsection{Fabrication of CS-MMT aerogel}

CS-MMT aerogel was prepared by sol-gel method (SI Fig. 1), which could be broken and 
regenerated at low temperature(SI Section 1). According to the absorbance value of $\mathrm{Cu}^{2+}$ in the supernatant, the concentration, adsorption capacity, and removal efficiency of $\mathrm{Cu}^{2+}$ in the remaining solution were calculated using equations ((1)-(4)).

$$
A=0.0191 C+0.0124
$$

$$
\begin{aligned}
& C e=\frac{C}{V_{1}} \\
& Q e=\left[\frac{\left(C_{0}-C_{e}\right) \times V_{2}}{m_{1}}\right] \\
& S(\%)=\frac{C_{0}-C_{e}}{C_{0}} \times 100 \%
\end{aligned}
$$

Where $C$ is the content of $\mathrm{Cu}^{2+}$ in the residual solution after adsorption, which can be calculated by different absorbance values $(\mu \mathrm{g})$. $C_{0}$ before for adsorption of $\mathrm{Cu}^{2+}$ solution concentration $(\mathrm{mg} / \mathrm{mL}) . C_{e}$ for the adsorption of $\mathrm{Cu}^{2+}$ solution concentration $(\mathrm{mg} / \mathrm{mL}) . m$ is obtained from the standard curve of $\mathrm{Cu}^{2+}$ dosage $(\mu \mathrm{g}) . m_{l}$ as adsorbent dose $(\mathrm{mg}) . V_{l}$ for copper water volume $(\mathrm{mL})$. $Q_{e}$ for equilibrium adsorption $\mathrm{Cu}$ (II) the amount of $(\mathrm{mg} / \mathrm{g}) . V_{2}$ to join $\mathrm{Cu}^{2+}$ the volume of a solution $(\mathrm{mL}), S$ for $\mathrm{Cu}^{2+}$ removal efficiency.

\section{Results and discussion}

\subsection{XPS, XRD and FT-IR analysis}



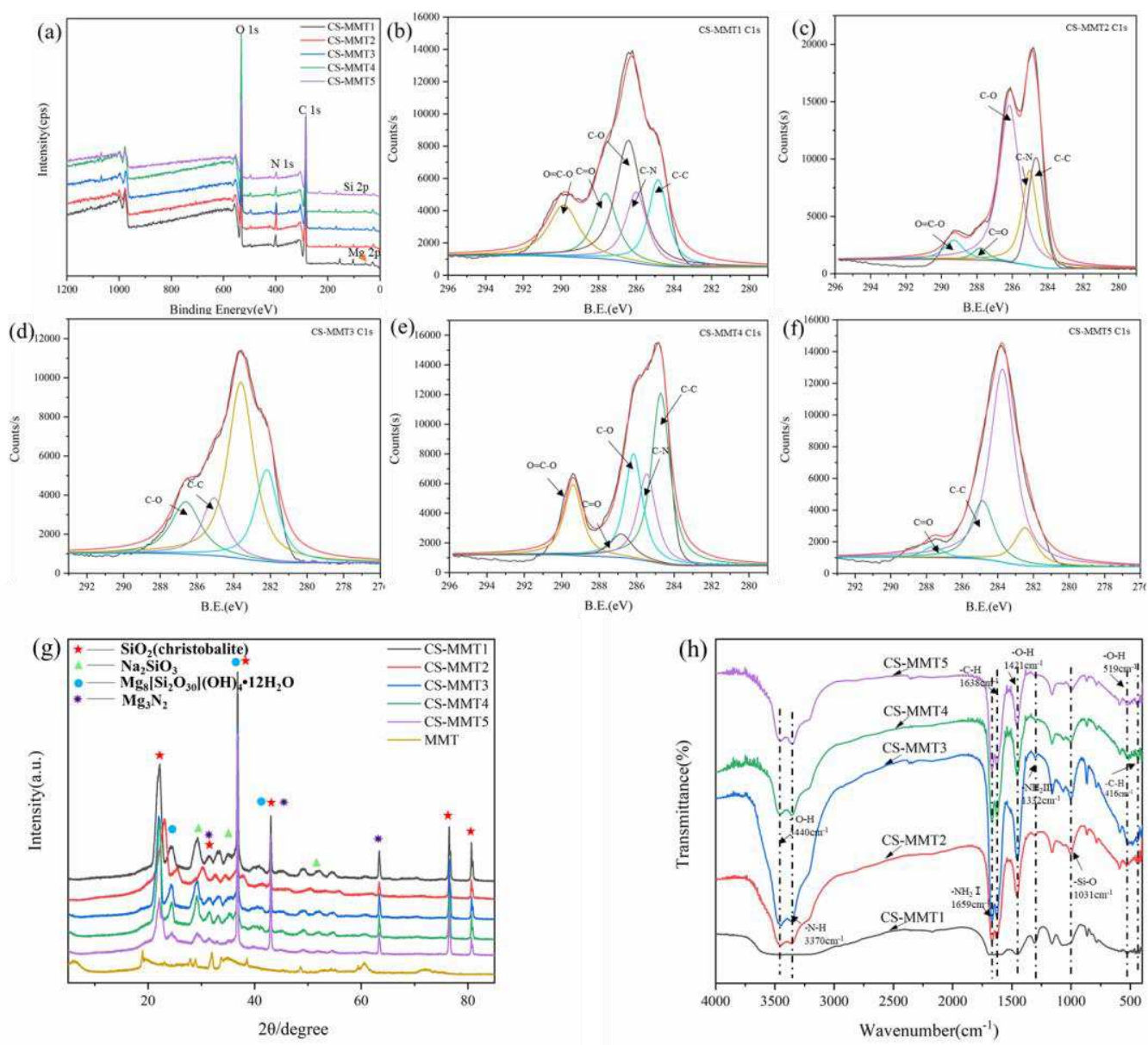

Fig. 1 (a) XPS survey spectrum, (b f) C1s spin-orbit peaks of CS-MMTs, (g) XRD patterns of CS-MMTs and MMT, (h) FTIR spectra of CS-MMTs

To further analyze the interaction between MMT and CS matrix, X-ray photoelectron spectroscopy is used to analyze the surface chemical state of different components of CS-MMTs (Fig. 1(b f)). The $\mathrm{C}$ spectrum shows that the CS-MMTs are rich in $\mathrm{C}-\mathrm{C}, \mathrm{C}=\mathrm{O}$, and $\mathrm{C}-\mathrm{O} / \mathrm{C}-\mathrm{N}$ groups.

The peak at $283.9 \mathrm{eV}$ corresponds to the binding energy of the $\mathrm{C}-\mathrm{N}$ bond, and the peaks of $\mathrm{C}=\mathrm{O}$ and

111 C-C mainly appear at about $286.8 \mathrm{eV}$ and $285.0 \mathrm{eV}$. (Wu et al. 2020). Compared with other components, the $\mathrm{C} 1 \mathrm{~s}$ of CS-MMT2 is significantly enhanced, and the intensity of the C-N peak is

113 also significantly increased, proving that MMT was successfully modified by CS. The O1s (531.8

$114 \mathrm{eV}$ ) peak is attributed to hydroxyl oxygen, indicating that siloxane was successfully converted to 
amount of C-N and N-O in CS-MMT. Besides, peaks of Si $2 \mathrm{p}(103 \mathrm{eV})$ and $\mathrm{Mg} 2 \mathrm{p}(55 \mathrm{eV})$ corresponding to MMT were found in the spectrum of CS-MMT2(Akar et al. 2020), indicating the successful combination of CS and MMT.

The crystal phase and phase composition of CS-MMT composite aerogel were analyzed by XRD (Fig. 1 (g)). According to extensive studies, MMT is a clay mineral in the form of octahedral crystals. The characteristic spikes show high crystallinity of nano-MMT at $5.9^{\circ}, 19^{\circ}$, and $26^{\circ}$. According to the Scherer equation, we can easily calculate that the interlayer spacing of nanomontmorillonite is $1.593 \mathrm{~nm}$. In contrast, the XRD patterns of the chitosan-modified montmorillonite composite aerogels have obvious changes, indicating that the crystal structure of the composite aerogel has changed significantly. By comparing and analyzing the standard spectra, we can infer that the crystal structure of CS-MMT is roughly the same as that of square quartz. Besides, we can notice that there is a broad peak at $29^{\circ}$. As the ratio of nano-montmorillonite increases, the peak intensity gradually decreases. We attribute this to the cation exchange between the protonated amino groups of chitosan and the cations in the montmorillonite layer, which results in such formation of disordered exfoliation structures.

As shown in Fig.1(h), the hydroxyl groups of amide or hydroxide combined with amino groups in montmorillonite and chitosan mainly appear at about $3400 \mathrm{~cm}^{-1}$, which is consistent with previous reports (Liu et al. 2020a). The amide stretching of the chitosan-modified montmorillonite composite appeared at about $1640 \mathrm{~cm}^{-1}$. All the CS-MMT composite aerogels showed characteristic silica sharp bands around $1031 \mathrm{~cm}^{-1}$. The bending vibrations of Si-O-Mg and Si-O-Si appeared at $1527 \mathrm{~cm}^{-1}$ and $470 \mathrm{~cm}^{-1}$, respectively(Zhu et al. 2017). There are strong peaks at $3440 \mathrm{~cm}-1$ and $1659 \mathrm{~cm}-1$, which correspond to the overlapping stretching vibrations of hydroxyl and amino groups and the stretching 
vibrations of carboxyl groups. The peak at $1332 \mathrm{~cm}^{-1}$ is the stretching vibration of amino. The FT-

IR is a great proof of the successful preparation of CS-MMT composite aerogels.

\subsection{SEM analysis}
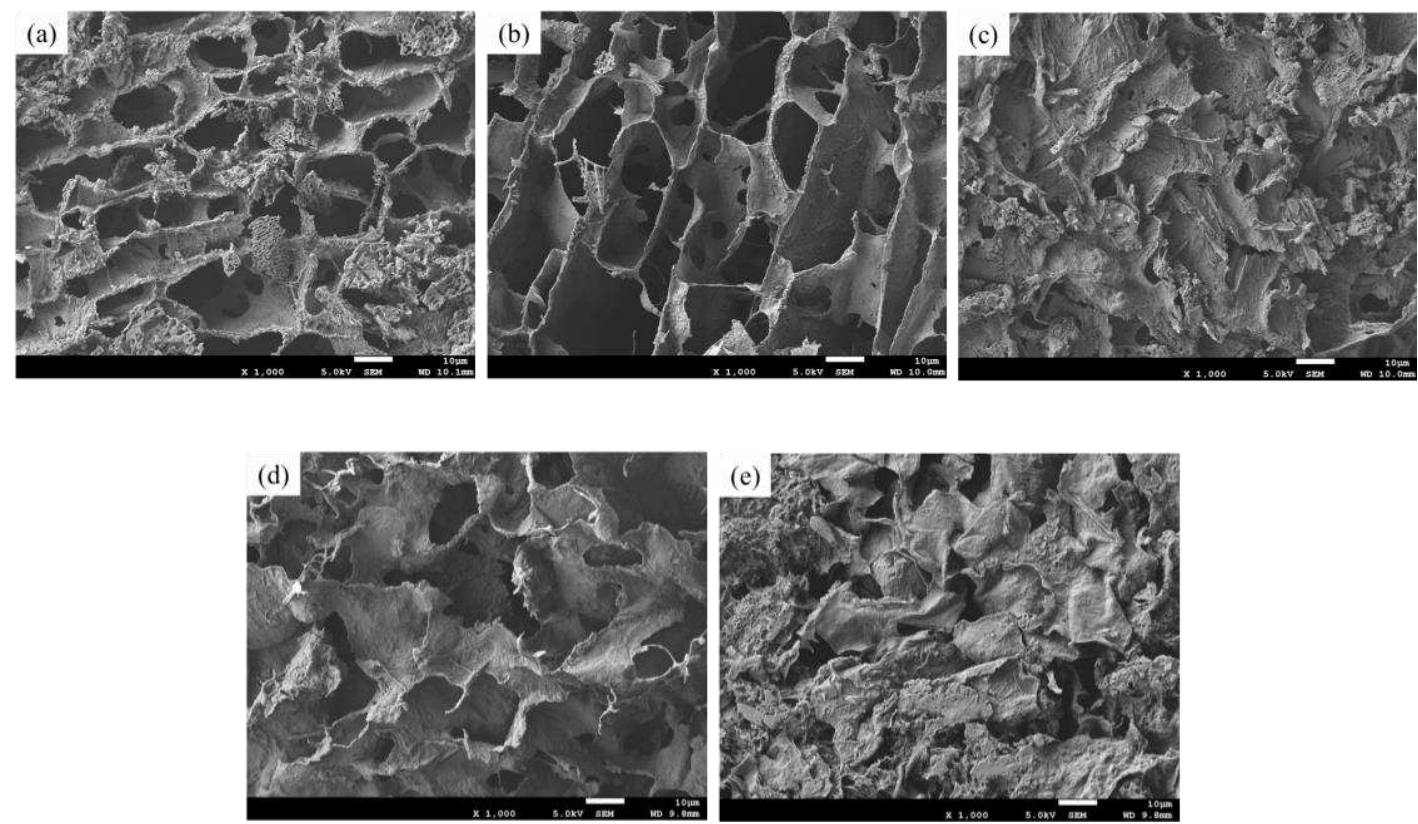

Fig. 2 SEM image of (a)CS-MMT1, (b)CS-MMT2, (c)CS-MMT3, (d)CS-MMT4, (e)CS-MMT5

As is shown in Fig. 2 , the CS-MMT composite aerogels of different components all present a clear layered structure. CS connects the montmorillonite laminates in a fiber-like cross-linking manner. As shown in Fig. 2(b), CS-MMT2 composite aerogel has a large number of thin-layer structures and a certain interlayer space. The doping of CS cross-links the layers of MMT to build a micron-level pore structure. This three-dimensional porous structure can greatly increase the specific surface area of the material, laying a solid foundation for the adsorption of heavy metal ions. The $\mathrm{C}, \mathrm{N}, \mathrm{O}$, and $\mathrm{Si}$ elements of CS-MMT2 aerogel are uniformly distributed. It contains a large number of oxygen-containing functional groups, oxides, and nitrides. By TG analysis, CSMMT showed higher degradation temperature (SI Section2, Fig. S2, and S3).

\subsection{The Specific surface area and pore size analysis}



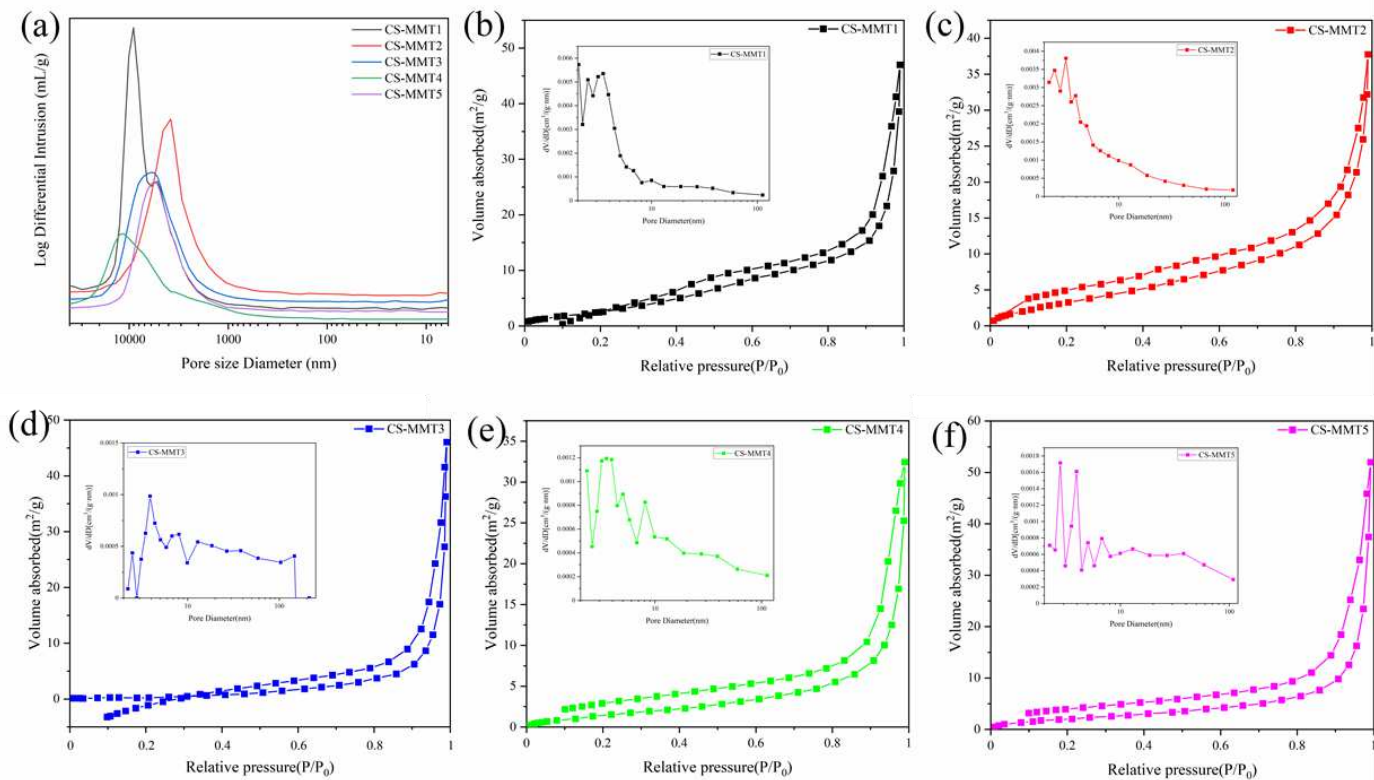

Fig. 3 (a) Mercury intrusion test, (b f) $\mathrm{N}_{2}$ Adsorption-desorption isotherms and pore size distributions of CS-MMT composite aerogels with different components

The shape of this type of hole should be a slit-like tubular capillary structure with both ends open. (Zhao et al. 2020). As is shown in Fig.3(a f), when the relative pressure $P / P_{0}$ was $0-0.6$, the $\mathrm{N}_{2}$ adsorption increased slowly, which proved that there were a few micropores in the samples. In this stage, nitrogen molecules are gradually adsorbed from monolayer to multilayer into the porous structure. Subsequently, when the relative pressure was between 0.6-0.99, the nitrogen adsorption capacity at the high-pressure end increased sharply, indicating the presence of mesopore and macropore in the material. According to the physical property parameters in SI Table S1, the specific surface area of CS-MMT2 is relatively high, which is $14.133 \mathrm{~m}^{2} / \mathrm{g}$, and the pore diameter distribution was uniform. Combined with SEM images(Fig.1(b)), it was found that there was a stable threedimensional network structure. (Chu et al. 2019). Because the nitrogen adsorption and desorption specific surface and pore size test can be widely used in the test of porous materials with mesoporous structure, it is only of reference value for macroporous materials. We conducted mercury intrusion 
tests on all five CS-MMT samples. According to the analysis of mercury injection pore size, the pores are mainly mesopore and macropore. The average pore sizes of composite aerogels are $1242.89 \mathrm{~nm}(\mathrm{CS}-\mathrm{MMT1}), 889.29 \mathrm{~nm}(\mathrm{CS}-\mathrm{MMT}), 1012.60 \mathrm{~nm}(\mathrm{CS}-\mathrm{MMT}), 3942.97 \mathrm{~nm}(\mathrm{CS}-$ MMT4), and $1159.19 \mathrm{~nm}(\mathrm{CS}-\mathrm{MMT}$ ). The pore size ranges from 50-100 $\mu \mathrm{m}$. Undoubtedly, large specific surface area and porous structure provided more abundant active sites for rapid absorption of $\mathrm{Cu}^{2+}$.

\subsection{Structure model and adsorption mechanism}

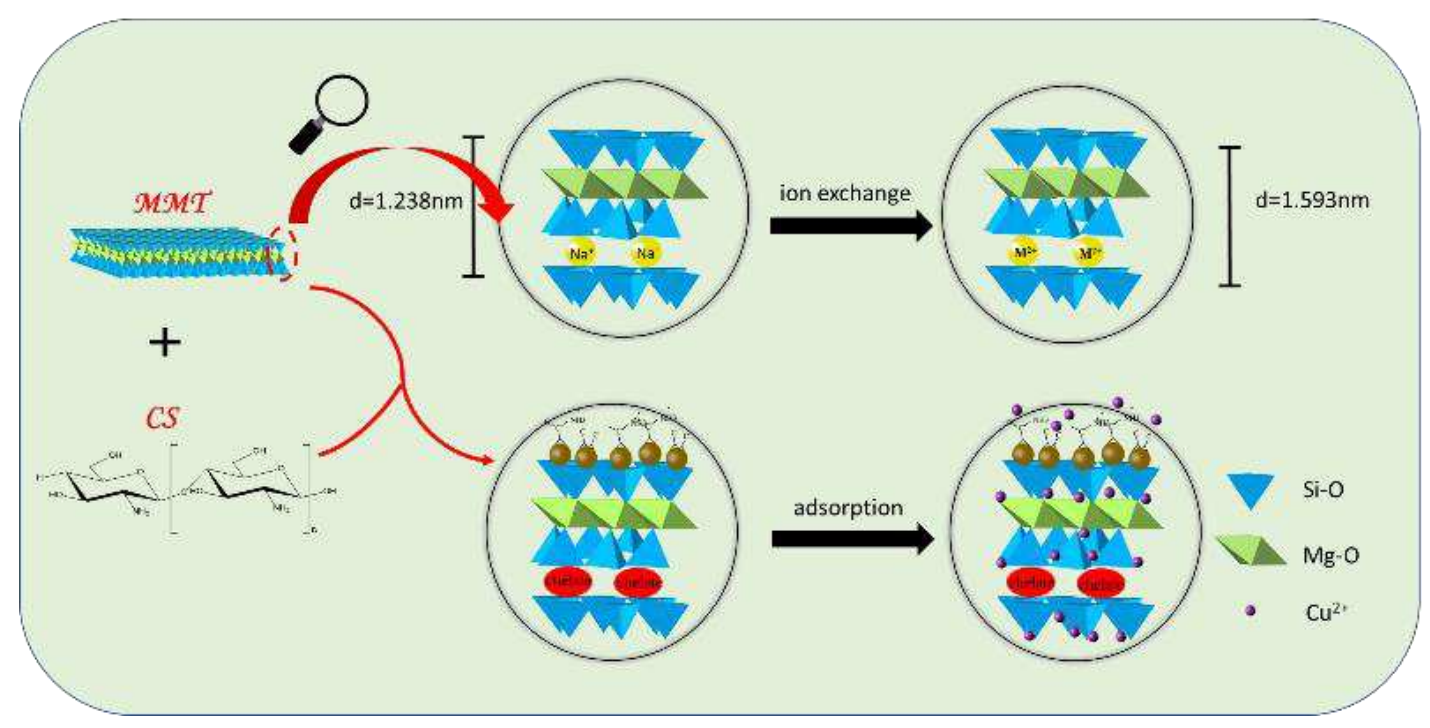

Fig. 4 Schematic diagram of structure model and adsorption mechanism

According to detailed characterization data, we can get the following material structure model

(Fig. 4). The montmorillonite layer is modified by organic quaternary ammonium salt ions.

Combined with the XRD diffraction pattern, it can be seen that the interlayer spacing of montmorillonite increases from 1.236 to $1.593 \mathrm{~nm}$. XRD, FT-IR, and XPS are used for detailed elements and surface state analysis. We speculate that strong alkali treatment and ball milling break the Si-O and Mg-O bonds of the unit cell in montmorillonite. The amino groups of chitosan crosslink the active bonds and the - $\mathrm{OH}$ and amino groups carried by the surface sheet, forming such CS- 
MMT composite aerogel. $\mathrm{Cu}^{2+}$ will not only chelate and react with the broken bonds on the surface of CS-MMT, at the same time, the pores and lamella structure of the aerogel are also positively related to the adsorption capacity.

\subsection{Adsorption property of CS-MMTs towards $\mathrm{Cu}^{2+}$}

\section{Adsorption equilibrium time and adsorption kinetics}

CS-MMT composite aerogel adsorbed $\mathrm{Cu}^{2+}$ at different times (SI Section 2). The adsorption rates of the five adsorbents at different times are sorted in Fig. 5. It can be seen from the adsorption curve and adsorption efficiency that all adsorbents have a high adsorption efficiency of $\mathrm{Cu}^{2+}$ in the initial stage of the adsorption reaction. As time goes on, the adsorption process slows down until an adsorption equilibrium is finally reached. In the initial stage of adsorption in this experiment, the $\mathrm{Cu}^{2+}$ adsorption material causes concentration diffusion in the solution, and the active adsorption sites on the montmorillonite can combine with $\mathrm{Cu}^{2+}$ at different adsorption rates and numbers. As the concentration gradient of $\mathrm{Cu}^{2+}$ decreases, the adsorption behavior on the adsorbent gradually decreases, which in turn causes the adsorption rate to slow down. At the same time, as the chelation reaction progresses, the adsorption sites are gradually occupied, and the adsorption reaction reaches equilibrium. From the relationship between adsorption time and adsorption efficiency, it can be seen that the adsorption efficiency of different components of CS-MMT composite aerogel on $\mathrm{Cu}^{2+}$ is not significantly different under the same experimental conditions. The adsorption efficiency of CS-MMT2 can be around 99\%, and the adsorption equilibrium was reached at about 50min, indicating that CS-MMT2 composite aerogel has a strong adsorption capacity for $\mathrm{Cu}^{2+}$. To elucidate the adsorption kinetics of CS-MMT composite aerogel on $\mathrm{Cu}^{2+}$, the quasi-first-order model (Eq5) and quasi-second-order model (Eq6) were used to fit the adsorption data of $\mathrm{Cu}^{2+}$ as follows: 


$$
\lg \left(Q_{e}-Q_{t}\right)=\lg Q_{e}-\frac{k_{1} t}{2.303}
$$

Where $Q_{e}$ is the adsorption amount when the adsorption process reaches adsorption equilibrium respectively.

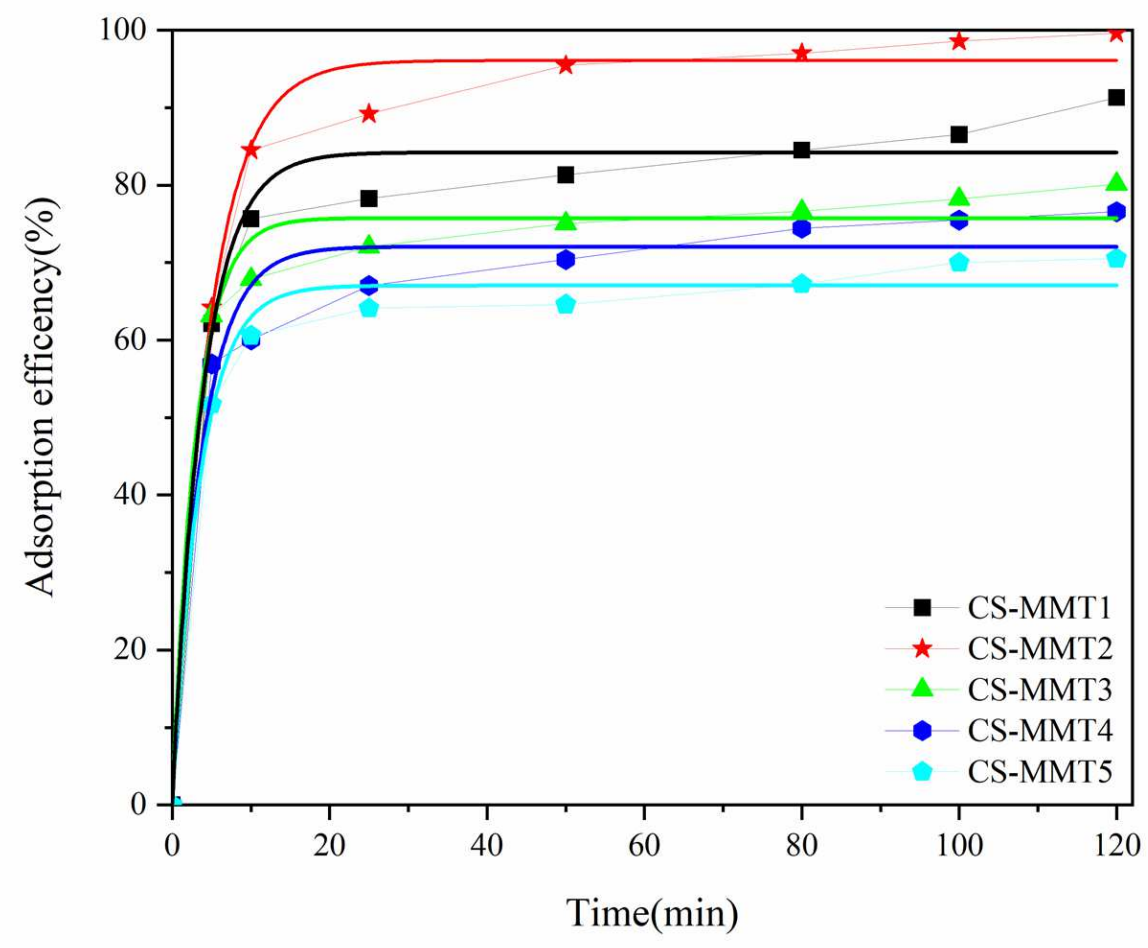

Fig. 5 Adsorption efficiency of CS-MMT composite aerogels for $\mathrm{Cu}^{2+}$ at different time

The parameters of the two models are shown in SI Table S2. By comparing the correlation coefficient $\mathrm{R}^{2}$ of the two models, it is obvious that the pseudo-second-order kinetic equation has a good correlation with the adsorption process. This indicates that the adsorption rate is more related to the number of unoccupied active sites. As the layered space of montmorillonite increases, the porosity increases. This will directly increase the number of active sites and increase the adsorption capacity 

correlation coefficient $\mathrm{R}^{2}$ was calculated. The $\mathrm{R}^{2}$ of CS-MMTs indicates that the adsorption of $\mathrm{Cu}^{2+}$ in

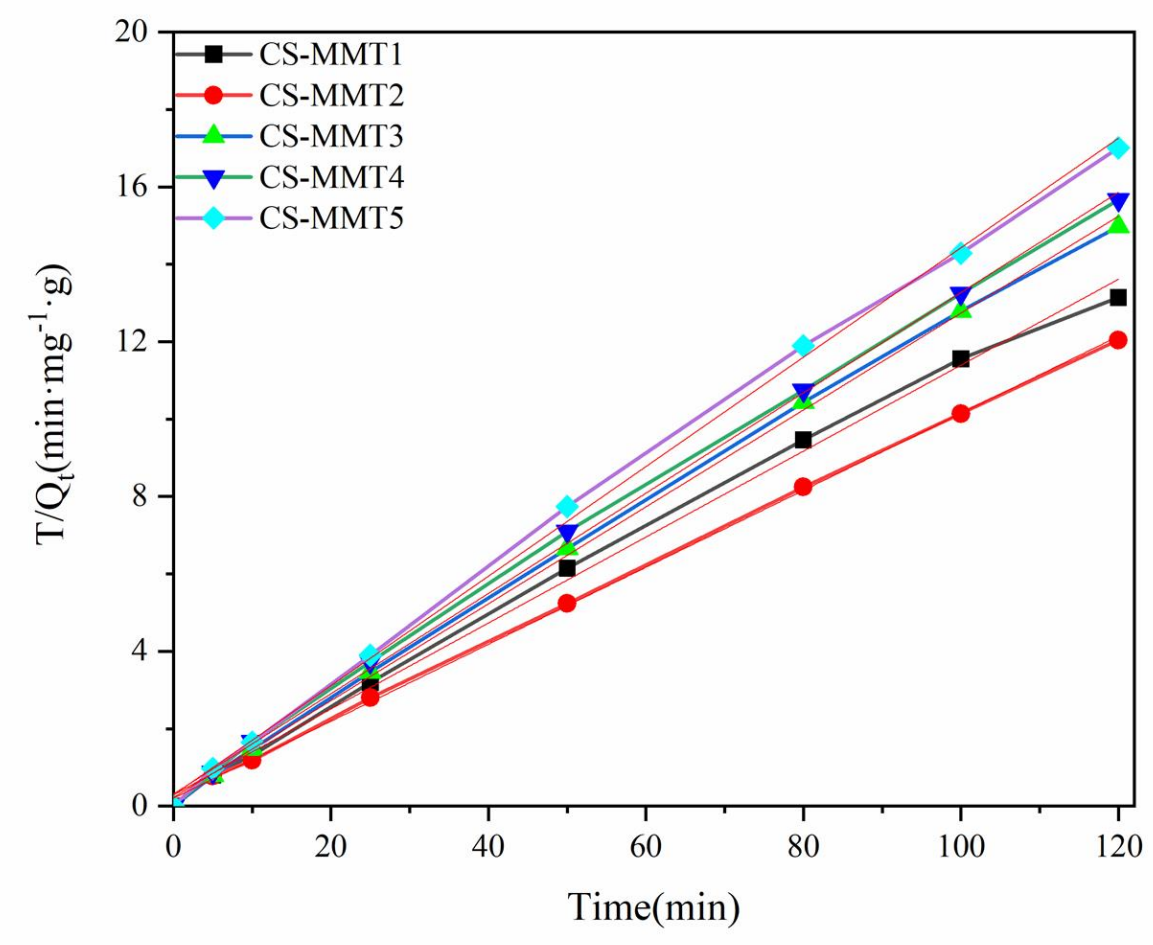

Fig. 6 Pseudo-second-order model for adsorption of $\mathrm{Cu}^{2+}$ on CS-MMT composite aerogels

\section{Adsorption isotherms and adsorption thermodynamics}

As can be seen from Fig. 7, the equilibrium adsorption capacity of the three adsorbents to copper ions increased with the increase of the initial concentration of $\mathrm{Cu}^{2+}$ solution until the adsorption was gradually slows down, and the curve flattens out to near saturation adsorption. 


$$
\frac{C_{e}}{Q_{e}}=\frac{C_{e}}{Q_{m}}+\frac{1}{K_{L} Q_{m}}
$$

$$
\ln Q_{e}=\ln K_{F}+\frac{1}{n} \ln C_{e}
$$

Where $\mathrm{Q}_{\mathrm{e}}$ is the adsorption amount of $\mathrm{Cu}^{2+}$ per unit mass of adsorbent at the adsorption equilibrium $(\mathrm{mg} / \mathrm{g}) \mathrm{Q}_{\mathrm{m}}$ represents the maximum adsorption capacity of $\mathrm{Cu}^{2+}(\mathrm{mg} / \mathrm{g})$, and $\mathrm{C}_{\mathrm{e}}$ represents the equilibrium concentration of $\mathrm{Cu}^{2+}$ after adsorption $(\mathrm{mg} / \mathrm{L})$, where $\mathrm{K}_{\mathrm{L}}$ and $\mathrm{K}_{\mathrm{F}}$ are the adsorption equilibrium constants of Langmuir isotherm equation and Freundlich isotherm equation, and $1 / \mathrm{n}$ is the heterogeneity factor. As can be clearly seen in Fig.10, the equilibrium adsorption capacity of the five adsorbents on $\mathrm{Cu}^{2+}$ showed a different increasing trend with the increase of the initial concentration of $\mathrm{Cu}^{2+}$ solution. When $\mathrm{Cu}^{2+}$ is at a low concentration, the adsorption curve rises very fast. When the initial concentration increases to a certain concentration, the increasing rate of adsorbent adsorption volume gradually slows down, and the curve flattens out until it approaches saturation adsorption. 


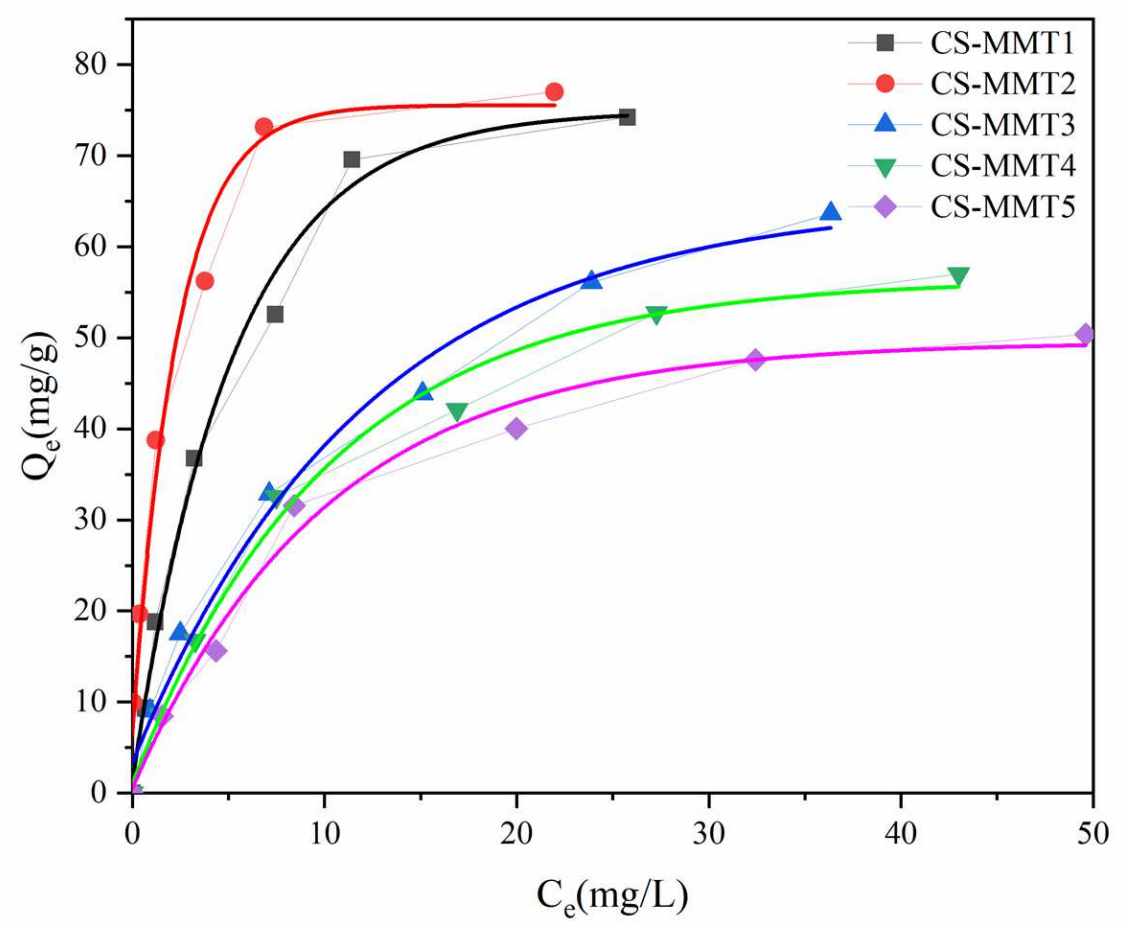

Fig. 7 Adsorption capacity of CS-MMT composite aerogels for $\mathrm{Cu}^{2+}$ in different initial solution

The adsorption data were correspondingly fitted to the Langmuir model. The fitting equations of

CS-MMTs are shown in Fig.8. The Langmuir and Freundlich parameters for adsorption of $\mathrm{Cu}^{2+}$ are sort in SI Table S3, respectively. The maximum adsorption capacity of the CS-MMTs on $\mathrm{Cu}^{2+}$ can be estimated according to the Langmuir adsorption model. Under the optimal conditions, the maximum adsorption capacities of CS-MMT composite aerogels for $\mathrm{Cu}^{2+}$ were estimated to be $80.38 \mathrm{mg} / \mathrm{g}$, $86.95 \mathrm{mg} / \mathrm{g}, 76.92 \mathrm{mg} / \mathrm{g}, 69.93 \mathrm{mg} / \mathrm{g}$, and $60.86 \mathrm{mg} / \mathrm{g}$, respectively. Compared with the montmorillonite adsorbent reported in the literature, the CS-MMT2 composite aerogel prepared by this experiment showed quite outstanding adsorption capacity for $\mathrm{Cu}^{2+}$ (Table 1). The digital image of the adsorption effect is shown in SI Fig. 4. With the addition of the adsorbent for about 30s, the blue complex will initially form until it becomes stable. After adsorption and centrifugation, the solution was obviously 


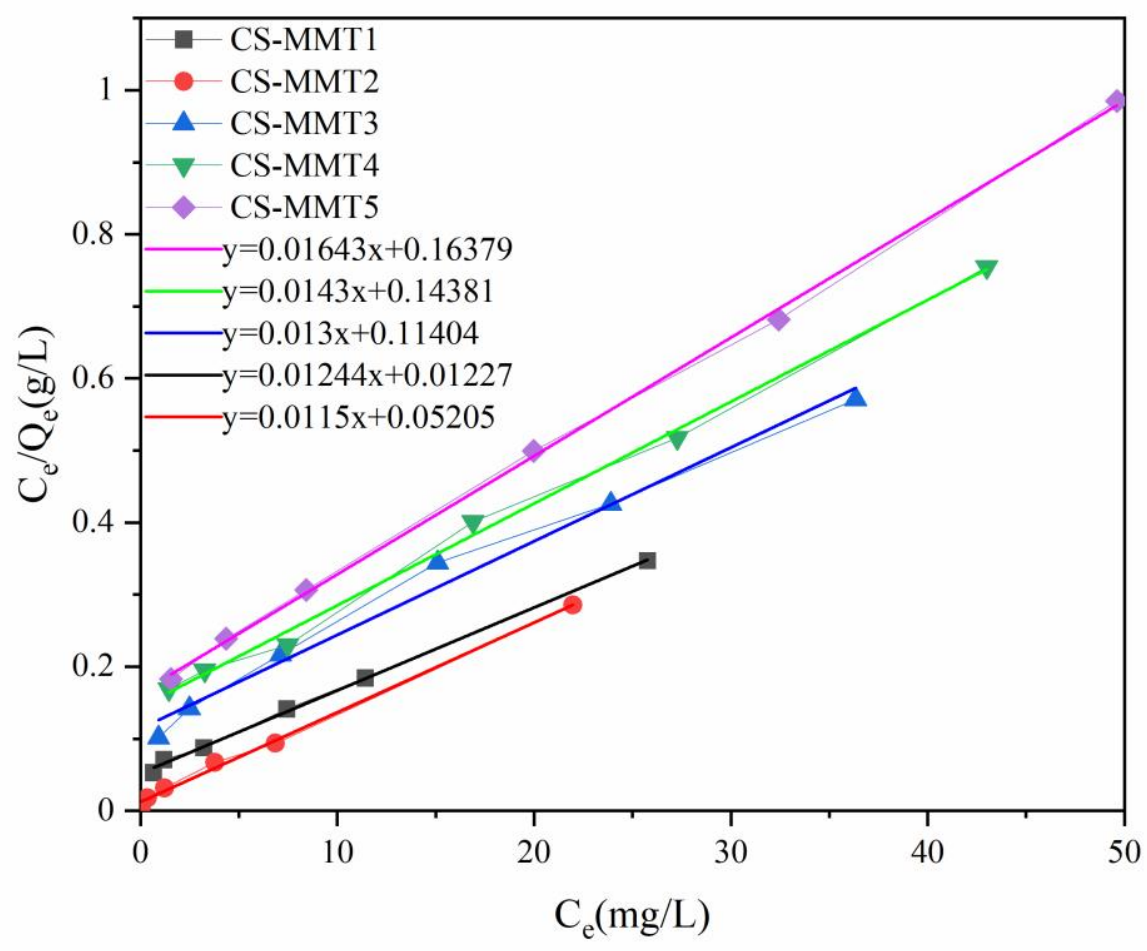

262

Fig. 8 Langmuir isotherms plots of $\mathrm{Cu}^{2+}$ adsorption on CS-MMTs

Table 1 Comparison with other published work

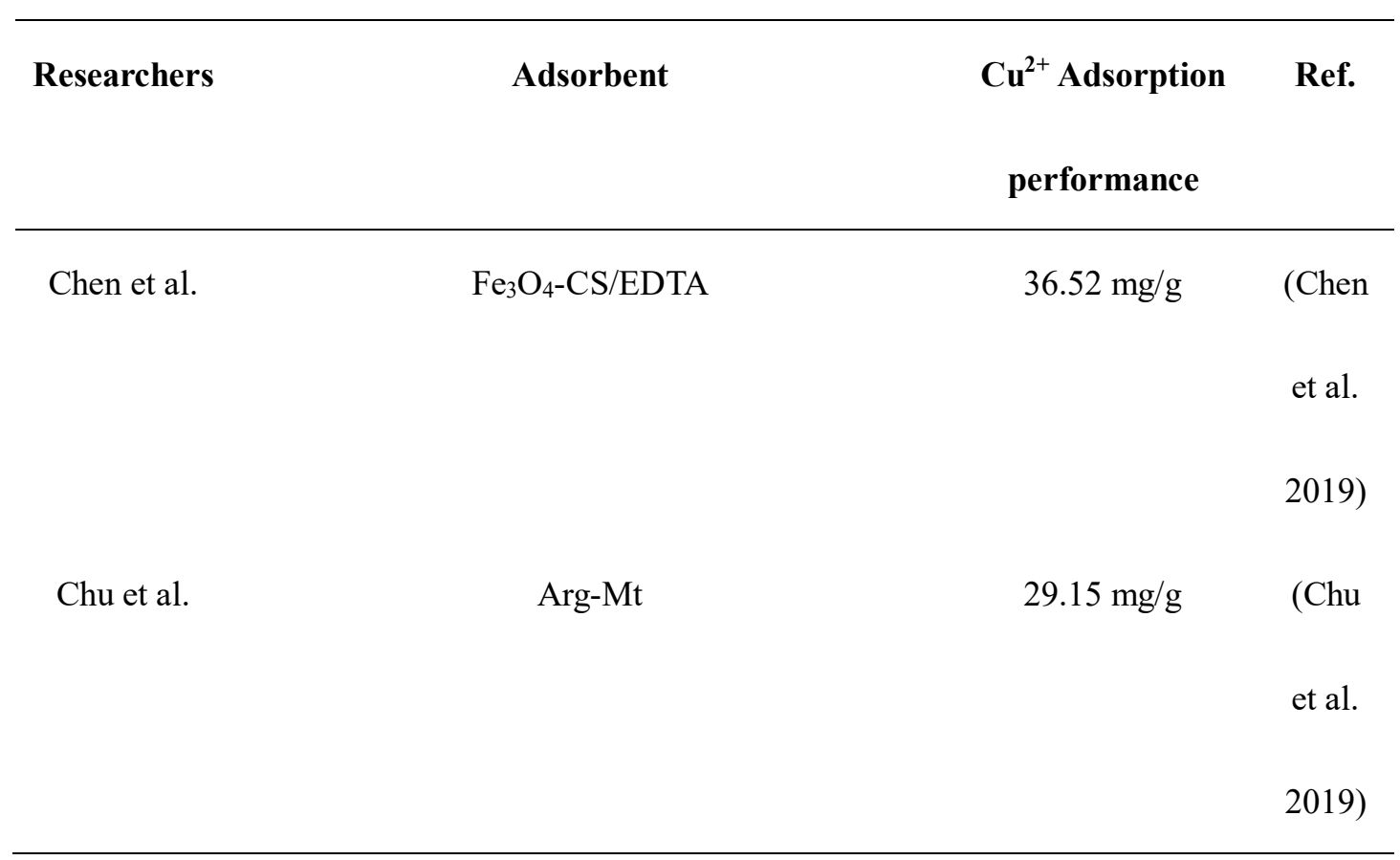


Chu et al. Histidine modifies montmorillonite

Montmorillonite was modified by diamino

surfactant-containing tetra ammonium cation

Magnetic bentonite/carboxymethyl

chitosan/sodium alginate hydrogel sphere

Wu et al. Magnetic polysaccharide/Go @ $\mathrm{Fe}_{3} \mathrm{O}_{4}$ gel beads

This work
CS-MMT

$86.95 \mathrm{mg} / \mathrm{g}$ 


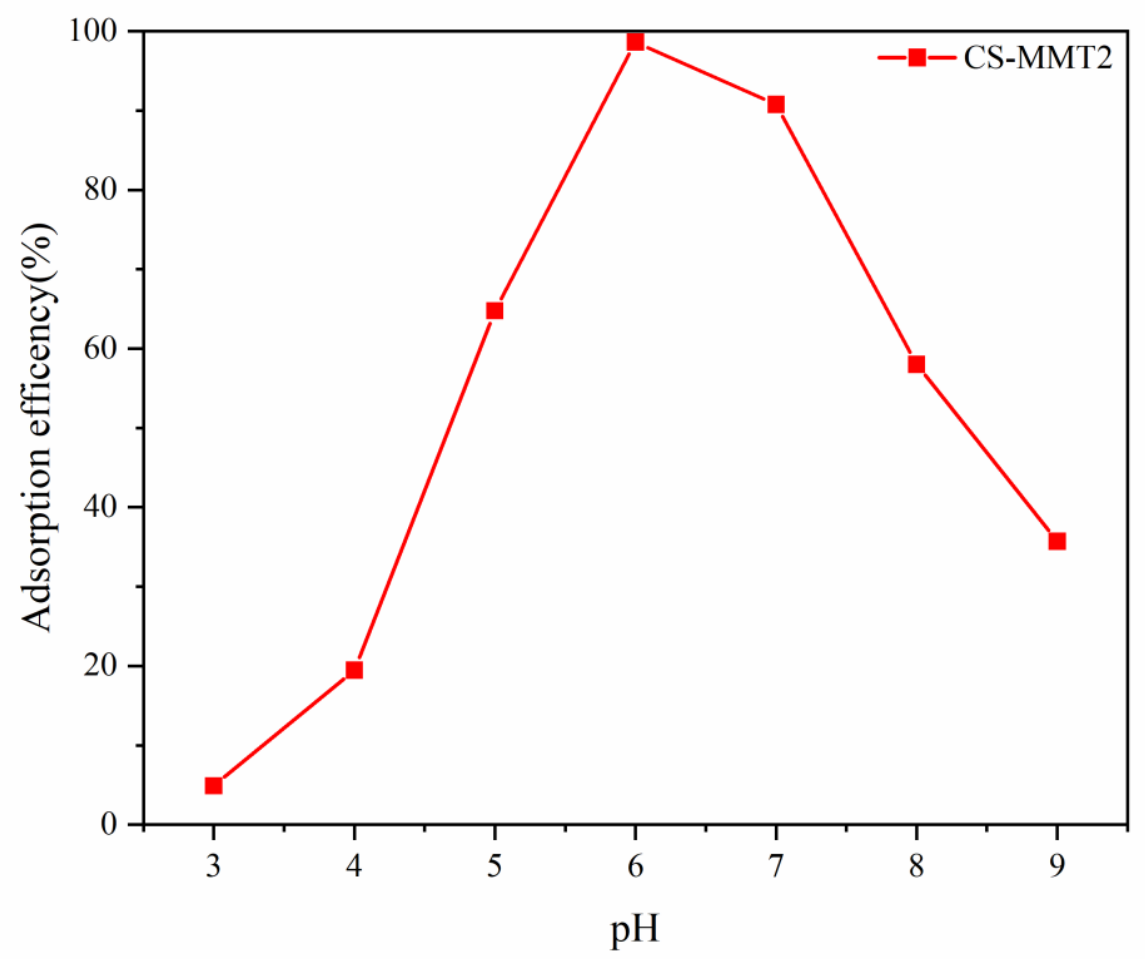

Fig. 9 The effect of solution $\mathrm{pH}$ value on the adsorption capacity of $\mathrm{Cu}^{2+}$ by CS-MMT2

It can be seen from Fig. 9 that the $\mathrm{Cu}^{2+}$ adsorption capacity of CS-MMT2 increases first and then decreases with the increase of the $\mathrm{pH}$ of the solution. When the solution is in a low $\mathrm{pH}$ range (3.0 4.0), the adsorption effect of CS-MMT2 is limited. This phenomenon can be interpreted as the presence of excess hydrogen ions under a low $\mathrm{pH}$ condition, which limits the reaction of chitosan and $\mathrm{NH}_{3}$ groups. Besides, CS is easy to dissolve in an acidic environment, which is the main reason for the limited adsorption capacity. When the $\mathrm{pH}$ value is higher than 4 , the adsorption capacity of $\mathrm{Cu}^{2+}$ increases significantly. As the $\mathrm{pH}$ of the solution increases, the number of hydrogen ions decreases, and protonation increases. There will be more adsorption sites on the surface of CS-MMT2, and the adsorption capacity will also show an increasing trend. At $\mathrm{pH}=6$, the adsorption capacity reached its peak and then began to decline. $\mathrm{Cu}^{2+}$ will form $\mathrm{Cu}(\mathrm{OH})_{2}$ precipitation at higher $\mathrm{pH}$ values. This shows from the side that the adsorption capacity of CS-MMT2 for $\mathrm{Cu}^{2+}$ decreases. Therefore, $\mathrm{pH}=6$ is the best service condition for 


\subsection{Adsorption cycle performance}

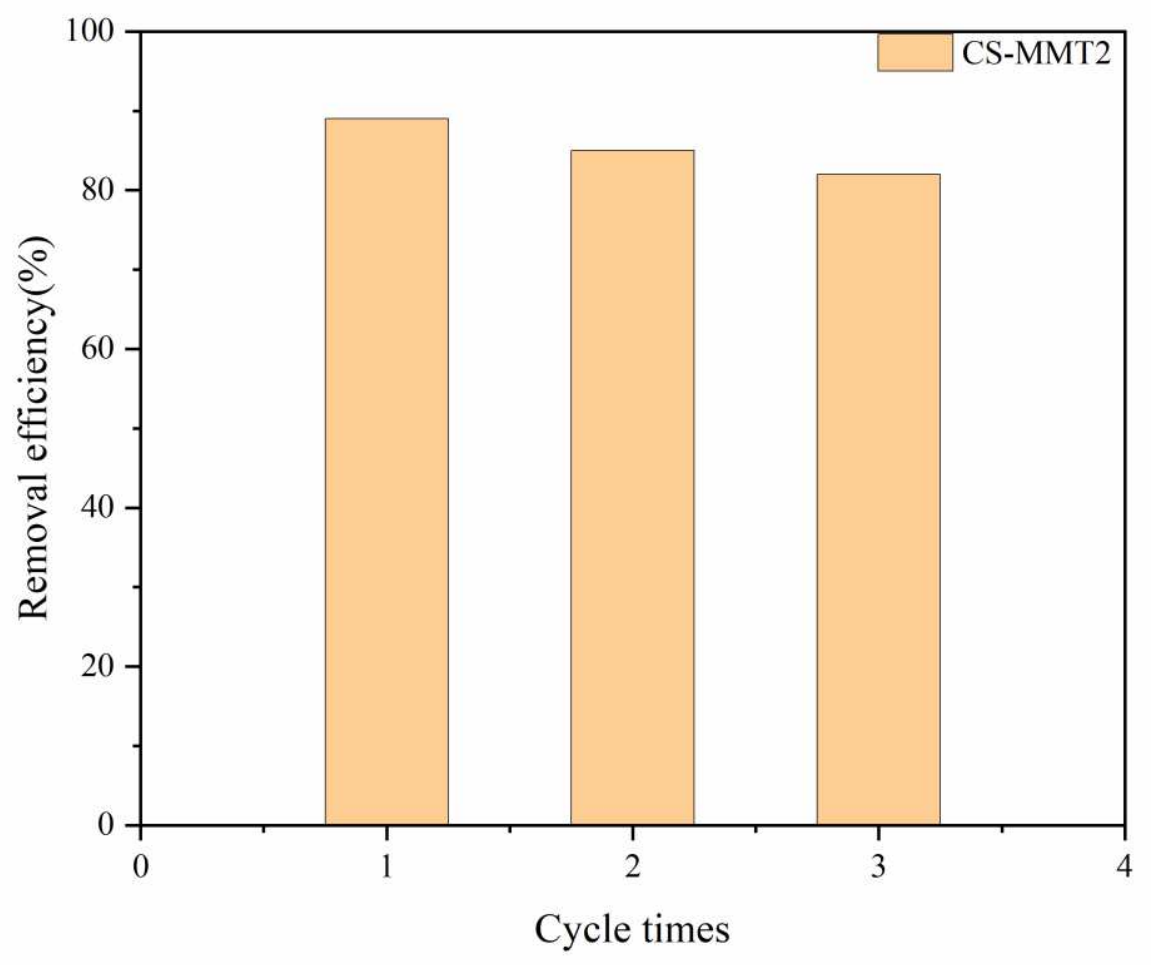

Fig. 10 Circulation capability of CS-MMT2

The regeneration efficiency of adsorbent is an important index to measure the actual use effect of an adsorbent. Generally speaking, effective adsorbent materials not only have high adsorption capacity but also have a great reuse effect. In this cycle experiment, we used a $0.2 \mathrm{~mol} / \mathrm{L}$ EDTA solution as the desorption solution. The three-cycle effect of CS-MMT2 was measured. The experimental results are shown in Fig. 10. After 3 times of adsorption-desorption, the adsorption efficiency of CS-MMT2 aerogel changed slightly and remained at about $80 \%$. EDTA mainly plays the role of chemically eluting $\mathrm{Cu}^{2+}$ in the desorption process and has a certain group repair effect on CS-MMT2. CS-MMT2 aerogel can be 
shrinkage and hole blockage are inevitable. This is due to the massive loss of CS-MMT surface groups during the adsorption and desorption process.

\subsection{Discussion on adsorption principle}
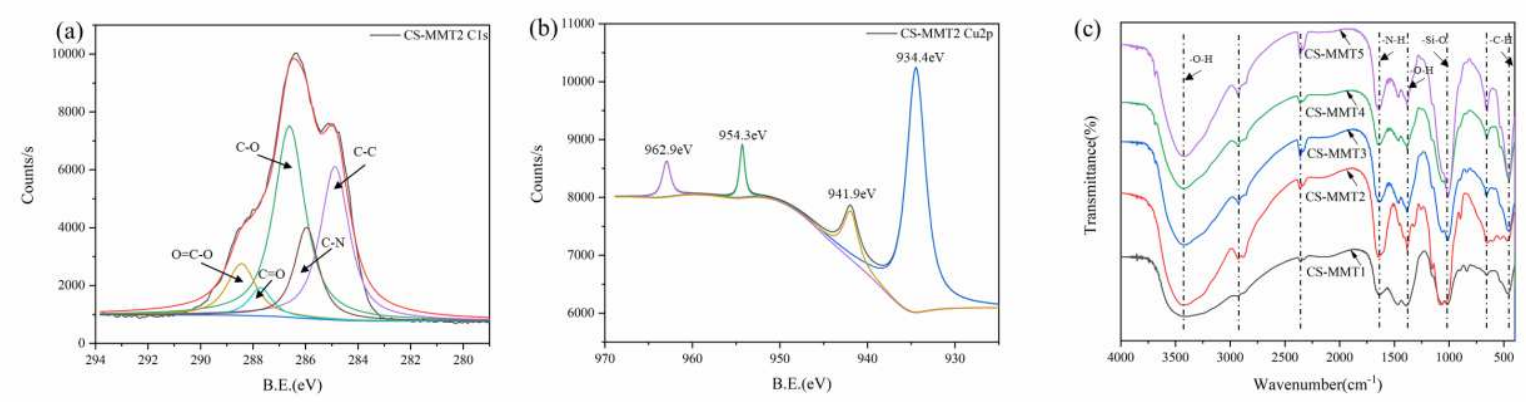

Fig. 11 (a) C1s, (b)Cu2p spin-orbit peaks of CS-MMT2 after adsorption, (c) FT-IR spectra of CS-

MMTs after adsorption

To explore the principle of adsorption, we characterized the adsorbed samples. As shown in Fig. 11(a), the C 1s spectra of CS-MMT2 were fitted with three components centered at 284.8, 285.9, 286.6.6, 287.7, and $288.4 \mathrm{eV}$, which can be assigned to $\mathrm{C}-\mathrm{C}, \mathrm{C}-\mathrm{N}, \mathrm{C}-\mathrm{O}, \mathrm{C}=\mathrm{O}$, and $\mathrm{O}=\mathrm{C}-\mathrm{O}$, respectively. The emergence of a new characteristic peak at $934.4 \mathrm{eV}$, corresponding to the presence of $\mathrm{Cu} 2 \mathrm{p}$ orbital. At the same time, the metal oxidation peak area was changed. $\mathrm{Cu}^{2+}$ reacted with the adsorbent to combine part of $\mathrm{O}$. It is the oxygen-containing functional group that participates in the adsorption process. The $\mathrm{Cu} 2 \mathrm{p}$ spin-orbit peaks showed that $\mathrm{Cu}^{2+}$ replaced the original hydrogen ion to form the corresponding complex. During the adsorption process, $\mathrm{C}-\mathrm{N}, \mathrm{C}-\mathrm{O}, \mathrm{O}=\mathrm{C}-\mathrm{O}$ content increased significantly, indicating that $\mathrm{Cu}^{2+}$ was successfully adsorbed on CS-MMT2. Therefore, it can be considered that the high adsorption capacity of CS-MMT2 to $\mathrm{Cu}^{2+}$ is due to chelating and stacking, and electrostatic attraction. As shown in Fig. 11(c), the intensity of the characteristic peak of the infrared spectrum changed to different degrees after copper ions were adsorbed, which indicats that amino, carboxyl, siloxane, and hydroxyl groups in CS-MMTS were involved in the 
adsorption of $\mathrm{Cu}^{2+}$.

\section{Conclusions}

CS-MMT composite aerogels were prepared by freeze-drying adsorption of $\mathrm{Cu}^{2+}$. Montmorillonite has a layered structure. Modifier and physical methods are used to enlarge the distance between the montmorillonite, and CS is grafted on the surface of montmorillonite. The surface contains a large number of active sites, which promote the cross-linking of chitosan and montmorillonite, forming a stable three-dimensional network structure. The experimental results show that CS-MMT2 has good adsorption performance for $\mathrm{Cu}^{2+}$.CS-MMT2 composite aerogel has a highly developed pore structure, high adsorption capacity, fast adsorption and desorption, and can effectively remove $\mathrm{Cu}^{2+}$ with remarkable effect. MMT first provides adsorption sites through cation exchange, and the amino group on the surface forms hydrogen bonds with the hydroxyl group of the chitosan, which promotes the cross-linking of the chitosan and montmorillonite in the soil. After 3 times of adsorption-desorption, the removal effect of CS-MMT2 composite aerogel on $\mathrm{Cu}^{2+}$ remains about $80 \%$. A feasible method was provided for the selective removal and effective recovery of $\mathrm{Cu}^{2+}$ from heavy metal wastewater.

\section{Acknowledgment}

This work was financially supported by the Key Research and Development Project of Jiangsu Province (BE2019734, BE2017151, BE2016171), the Major Program of Natural Science Fund in Colleges and Universities of Jiangsu Province(15KJA430005), the Program of Science and Technology of Suqian City(M201704, H201801, H201803), the National Natural Science Foundation of China (51702156, 81471183), the Program for Changjiang Scholars and Innovative Research Team in University (IRT_15R35), the Priority Academic Program Development of Jiangsu Higher Education Institutions and the Brand Major Program Development of Jiangsu Higher Education Institutions 
reflect the views of these programs.

\section{References}

Akar ST, Sayin F, Ozdemir I, Tunc D (2020) A Natural Montmorillonite-Based Magsorbent as an Effective Scavenger for Cadmium Contamination Water Air and Soil Pollution 231 doi:10.1007/s11270-020-04743-3

Baetens R, Jelle BP, Gustavsen A (2011) Aerogel insulation for building applications: A state-of-the-art review Energy and Buildings 43:761-769 doi:10.1016/j.enbuild.2010.12.012

Bailey SE, Olin TJ, Bricka RM, Adrian DD (1999) A review of potentially low-cost sorbents for heavy metals Water Res 33:2469-2479 doi:Doi 10.1016/S0043-1354(98)00475-8

Chen B, Zhao H, Chen S, Long F, Huang B, Yang B, Pan X (2019) A magnetically recyclable chitosan composite adsorbent functionalized with EDTA for simultaneous capture of anionic dye and heavy metals in complex wastewater Chemical Engineering Journal 356:69-80 doi:10.1016/j.cej.2018.08.222

Chu Y, Khan MA, Wang F, Xia M, Lei W, Zhu S (2019) Kinetics and equilibrium isotherms of adsorption of $\mathrm{Pb}(\mathrm{II})$ and $\mathrm{Cu}(\mathrm{II})$ onto raw and arginine-modified montmorillonite Advanced Powder Technology 30:1067-1078 doi:10.1016/j.apt.2019.03.002

Chu Y, Khan MA, Xia M, Lei W, Wang F, Zhu S, Yan X (2020) Synthesis and micro-mechanistic studies of histidine modified montmorillonite for lead(II) and copper(II) adsorption from wastewater Chemical Engineering Research \& Design 157:142-152 doi:10.1016/j.cherd.2020.02.020

Cui S et al. (2018) Preparation of magnetic MnFe2O4-Cellulose aerogel composite and its kinetics and thermodynamics of $\mathrm{Cu}(\mathrm{II})$ adsorption Cellulose 25:735-751 doi:10.1007/s10570-017-1598-x

El-Kousy SM, El-Shorbagy HG, Abd El-Ghaffar MA (2020) Chitosan/montmorillonite composites for fast removal of methylene blue from aqueous solutions Mater Chem Phys 254 doi:ARTN 123236

10.1016/j.matchemphys.2020.123236

Fu FL, Wang Q (2011) Removal of heavy metal ions from wastewaters: A review J Environ Manage 92:407-418 doi:10.1016/j.jenvman.2010.11.011 
Guo $\mathrm{T}$ et al. (2019) Bioinspired self-assembled films of carboxymethyl cellulosedopamine/montmorillonite Journal of Materials Chemistry A 7:14033-14041 doi:10.1039/c9ta00998a

Hu C, Li GY, Wang YY, Li FY, Guo GG, Hu HQ (2017a) The effect of pH on the bonding of Cu2+ and chitosan-montmorillonite composite Int J Biol Macromol 103:751-757 doi:10.1016/j.ijbiomac.2017.05.065

Hu C, Zhu PF, Cai M, Hu HQ, Fu QL (2017b) Comparative adsorption of Pb(II), Cu(II) and Cd(II) on chitosan saturated montmorillonite: Kinetic, thermodynamic and equilibrium studies Appl Clay Sci 143:320-326 doi:10.1016/j.clay.2017.04.005

Jarup L (2003) Hazards of heavy metal contamination Brit Med Bull 68:167-182 doi:10.1093/bmb/ldg032

Kolpin DW, Furlong ET, Meyer MT, Thurman EM, Zaugg SD, Barber LB, Buxton HT (2002) Pharmaceuticals, hormones, and other organic wastewater contaminants in US streams, 19992000: A national reconnaissance Environmental Science \& Technology 36:1202-1211 doi:10.1021/es011055j

Li A, Lin RJ, Lin C, He BY, Zheng TT, Lu LB, Cao Y (2016) An environment-friendly and multifunctional absorbent from chitosan for organic pollutants and heavy metal ion Carbohyd Polym 148:272-280 doi:10.1016/j.carbpol.2016.04.070

Liu P, Fan G, Wang J, Zhou G, Cao Y, Han X, Xu X (2020a) Biomimetic mineralization of montmorillonite-based nanomaterials for efficient capture of copper ions Appl Clay Sci 195 doi:10.1016/j.clay.2020.105720

Liu P, Fan GX, Wang JT, Zhou GL, Cao YJ, Han XK, Xu XQ (2020b) Biomimetic mineralization of montmorillonite-based nanomaterials for efficient capture of copper ions Appl Clay Sci 195 doi:ARTN 105720

10.1016/j.clay.2020.105720

Luo P, Zhao YF, Zhang B, Liu JD, Yang Y, Liu JF (2010) Study on the adsorption of Neutral Red from aqueous solution onto halloysite nanotubes Water Res 44:1489-1497 doi:10.1016/j.watres.2009.10.042

Mahouachi L, Rastogi T, Palm W-U, Ghorbel-Abid I, Chehimi DBH, Kuemmerer K (2020) Natural clay as a sorbent to remove pharmaceutical micropollutants from wastewater Chemosphere 258 doi:10.1016/j.chemosphere.2020.127213

Moja TN, Bunekar N, Mishra SB, Tsai TY, Hwang SS, Mishra AK (2020) Melt processing of polypropylene-grafted-maleic anhydride/Chitosan polymer blend functionalized with montmorillonite for the removal of lead ions from aqueous solutions Sci Rep-Uk 10 doi:ARTN 217

10.1038/s41598-019-57079-2

Pierre AC, Pajonk GM (2002) Chemistry of aerogels and their applications Chem Rev 102:4243-4265 doi: $10.1021 / \mathrm{cr} 0101306$

Qin L et al. (2020) Preparation of ion-imprinted montmorillonite nanosheets/chitosan gel beads for selective recovery of $\mathrm{Cu}(\mathrm{II})$ from wastewater Chemosphere 252 doi:ARTN 126560

10.1016/j.chemosphere.2020.126560

Shabbir Z et al. (2020) Copper uptake, essentiality, toxicity, detoxification and risk assessment in soilplant environment Chemosphere 259 doi:ARTN 127436

10.1016/j.chemosphere.2020.127436 
Sun YB, Sun GH, Xu YM, Wang L, Liang XF, Lin DS (2013) Assessment of sepiolite for immobilization of cadmium-contaminated soils Geoderma 193:149-155 doi:10.1016/j.geoderma.2012.07.012

Thit A, Banta GT, Palmqvist A, Selck H (2020) Effects of sediment-associated Cu on Tubifex tubifex Insights gained by standard ecotoxicological and novel, but simple, bioturbation endpoints Environ Pollut 266 doi:ARTN 115251

10.1016/j.envpol.2020.115251

Uddin MK (2017) A review on the adsorption of heavy metals by clay minerals, with special focus on the past decade Chemical Engineering Journal 308:438-462 doi:10.1016/j.cej.2016.09.029

Wan MW, Kan CC, Rogel BD, Dalida MLP (2010) Adsorption of copper (II) and lead (II) ions from aqueous solution on chitosan-coated sand Carbohyd Polym 80:891-899 doi:10.1016/j.carbpol.2009.12.048

Wang R, Shou D, Lv O, Kong Y, Deng LH, Shen J (2017) pH-Controlled drug delivery with hybrid aerogel of chitosan, carboxymethyl cellulose and graphene oxide as the carrier Int J Biol Macromol 103:248-253 doi:10.1016/j.ijbiomac.2017.05.064

Wu HP et al. (2020) Cetylpyridinium bromide/montmorillonite-graphene oxide composite with good antibacterial activity Biomed Mater 15 doi:ARTN 055002

$10.1088 / 1748-605 \mathrm{X} / \mathrm{ab} 8440$

Wu HS, Zhang AQ, Wang LS (2004) Immobilization study of biosorption of heavy metal ions onto activated sludge J Environ Sci-China 16:640-645

Wu Z, Deng W, Zhou W, Luo J (2019) Novel magnetic polysaccharide/graphene oxide@Fe3O4 gel beads for adsorbing heavy metal ions Carbohyd Polym 216:119-128 doi:10.1016/j.carbpol.2019.04.020

Yuan P, Tan DY, Annabi-Bergaya F (2015) Properties and applications of halloysite nanotubes: recent research advances and future prospects Appl Clay Sci 112:75-93 doi:10.1016/j.clay.2015.05.001

Zhang H, Omer AM, Hu Z, Yang L-Y, Ji C, Ouyang X-k (2019) Fabrication of magnetic bentonite/carboxymethyl chitosan/sodium alginate hydrogel beads for $\mathrm{Cu}$ (II) adsorption Int $\mathrm{J}$ Biol Macromol 135:490-500 doi:10.1016/j.ijbiomac.2019.05.185

Zhao Y, Zhong K, Liu W, Cui S, Zhong Y, Jiang S (2020) Preparation and oil adsorption properties of hydrophobic microcrystalline cellulose aerogel Cellulose doi:10.1007/s10570-020-03309-0

Zhu L, Wang L, Xu Y (2017) Chitosan and surfactant co-modified montmorillonite: A multifunctional adsorbent for contaminant removal Appl Clay Sci 146:35-42 doi:10.1016/j.clay.2017.05.027

Zou Y et al. (2016) Environmental Remediation and Application of Nanoscale Zero-Valent Iron and Its Composites for the Removal of Heavy Metal Ions: A Review Environmental Science \& Technology 50:7290-7304 doi:10.1021/acs.est.6b01897 

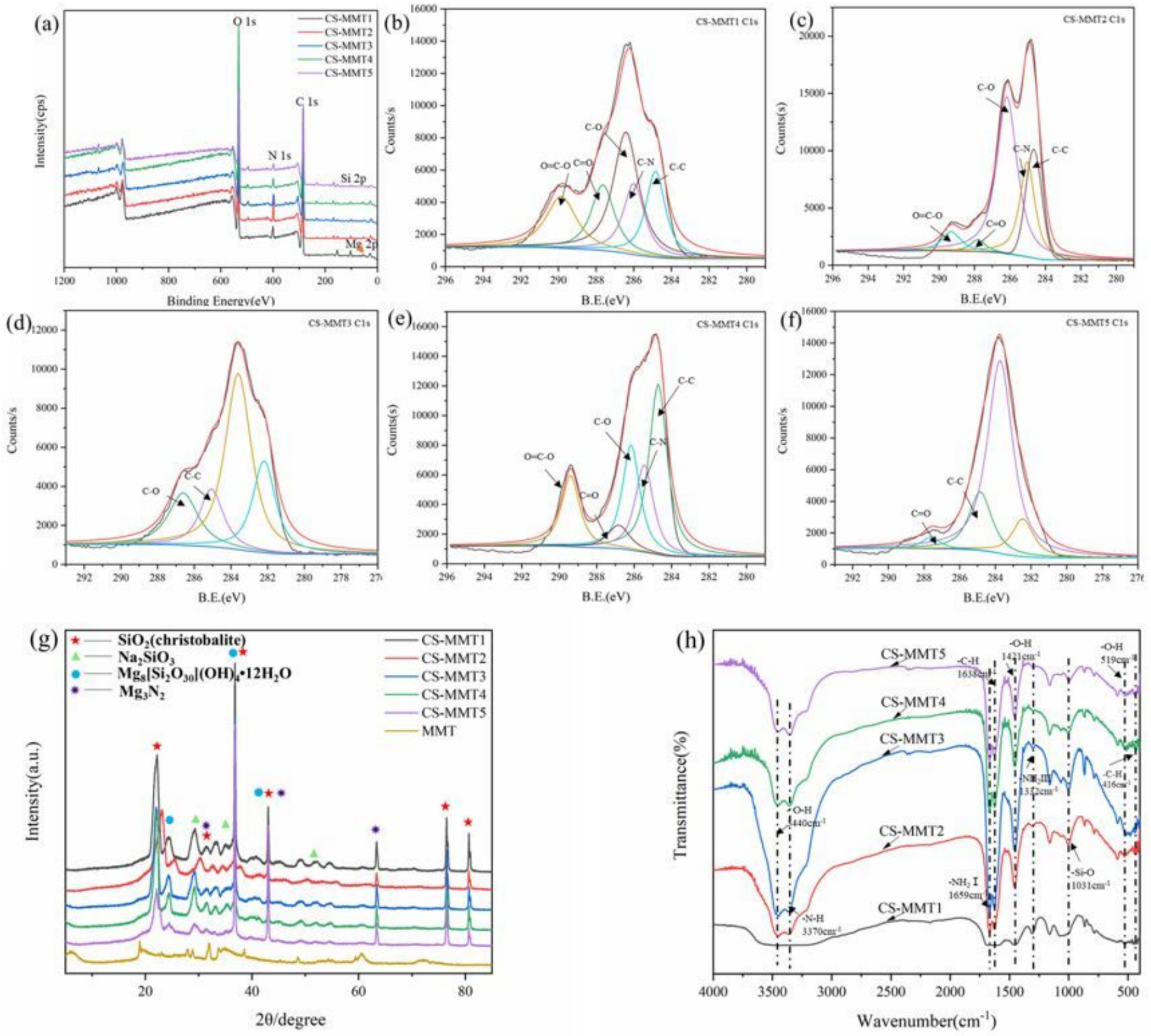

Figure 1

(a) XPS survey spectrum, (b f) C1s spin-orbit peaks of CS-MMTs, (g) XRD patterns of CS-MMTs and MMT, (h) FTIR spectra of CS-MMTs 

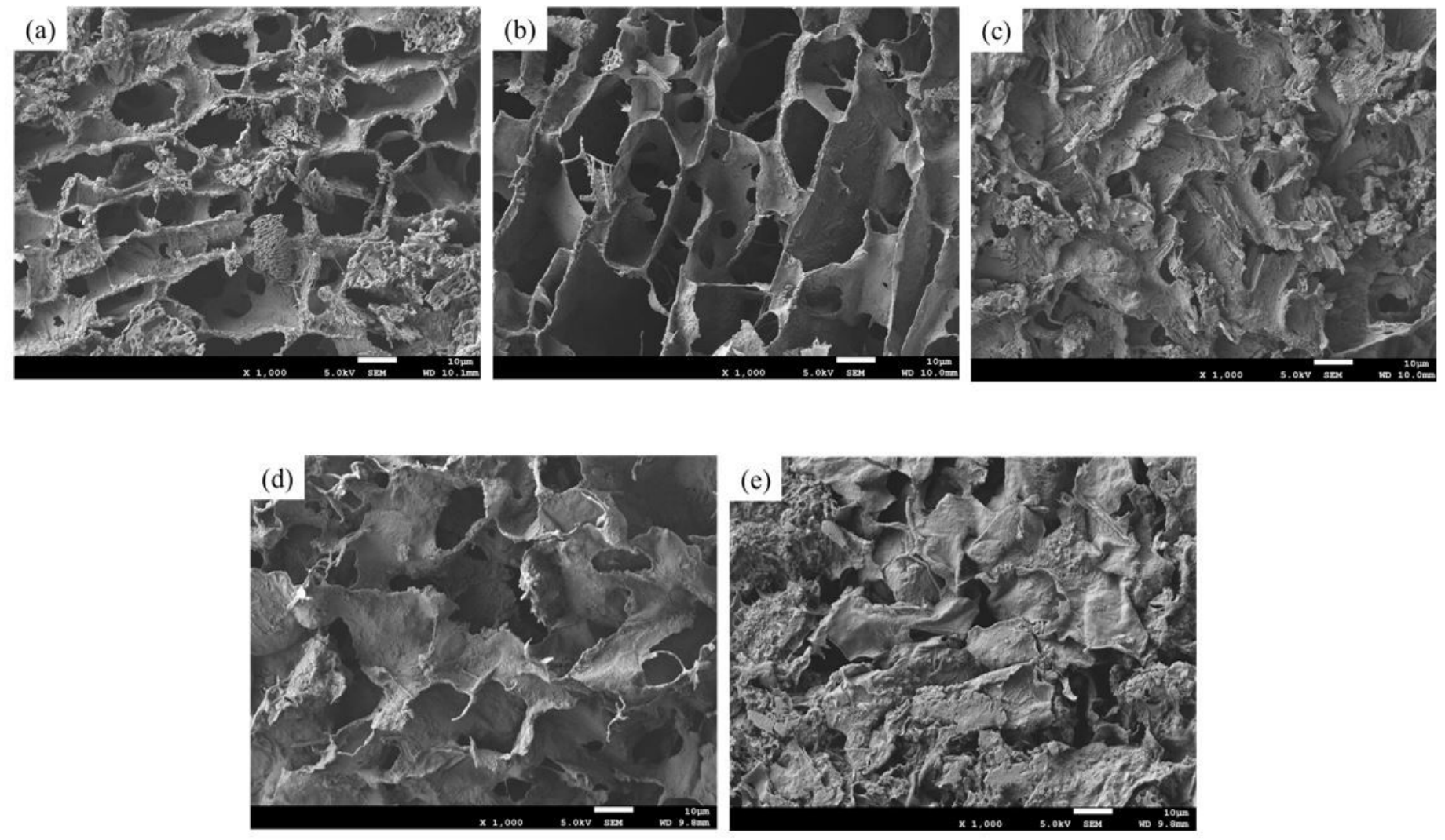

Figure 2

SEM image of (a)CS-MMT1, (b)CS-MMT2, (c)CS-MMT3, (d)CS-MMT4, (e)CS-MMT5 

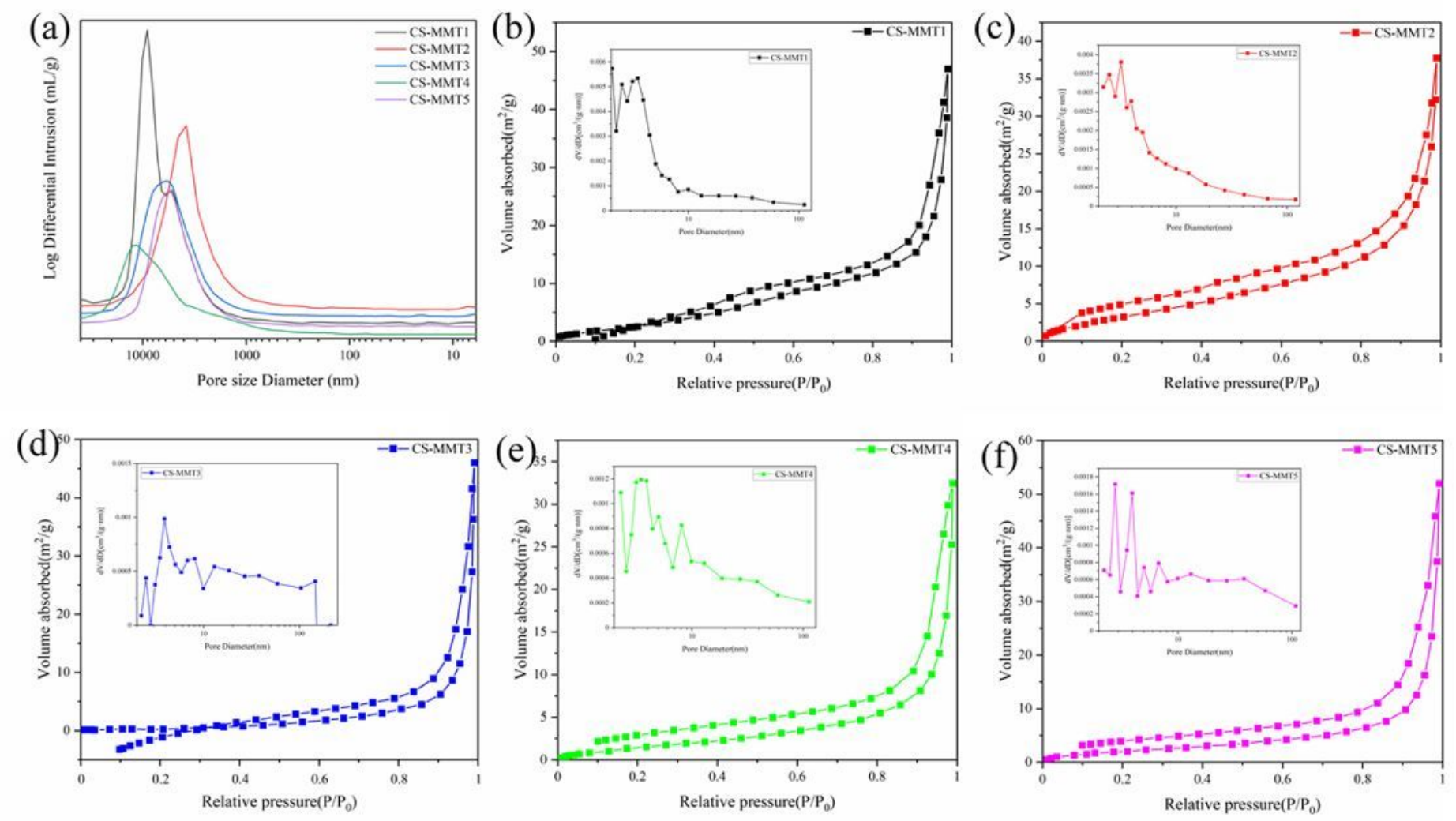

\section{Figure 3}

(a) Mercury intrusion test, (b f) N2 Adsorption-desorption isotherms and pore size distributions of CSMMT composite aerogels with different components

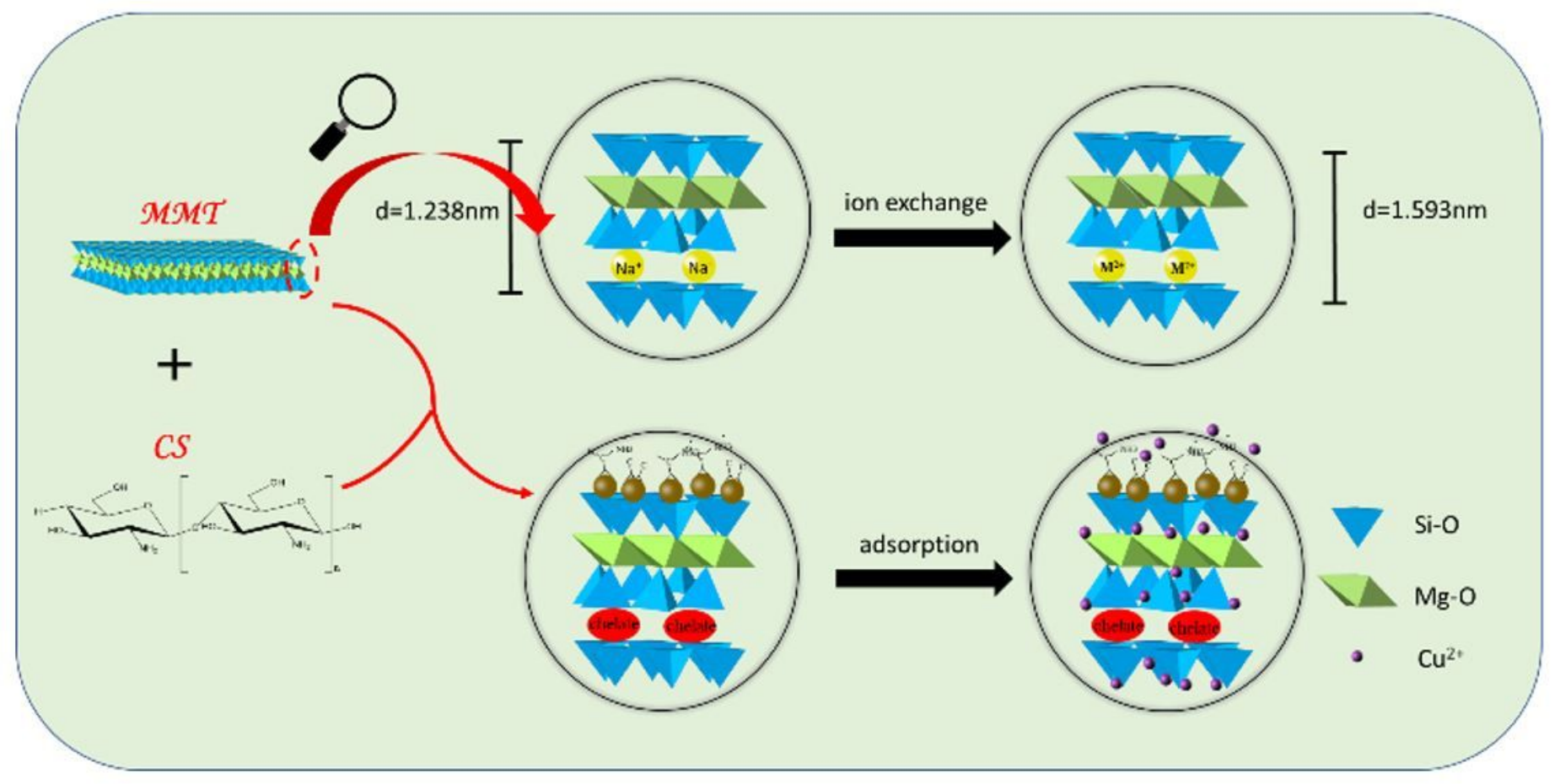


Figure 4

Schematic diagram of structure model and adsorption mechanism

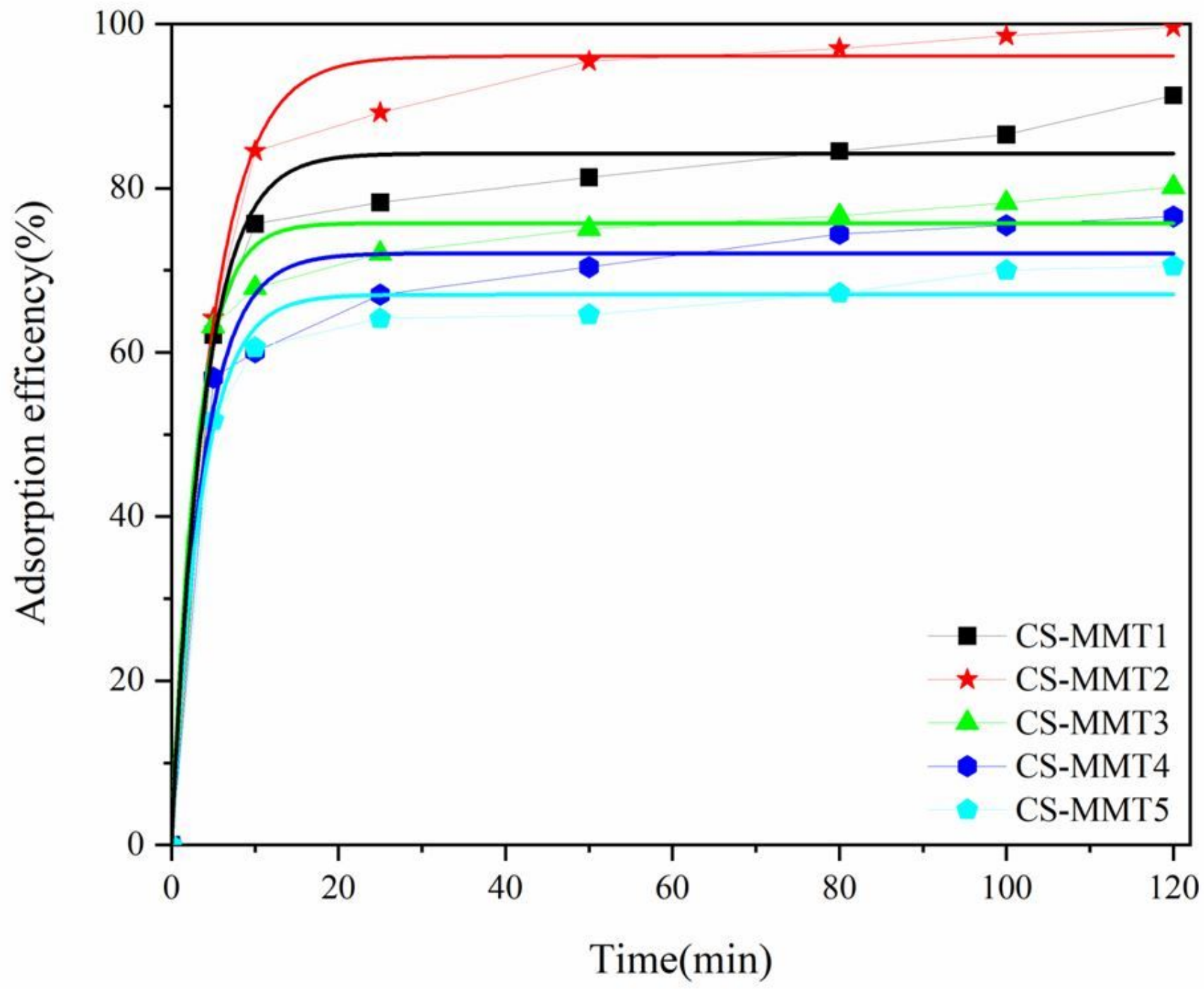

Figure 5

Adsorption efficiency of CS-MMT composite aerogels for Cu2+ at different time 


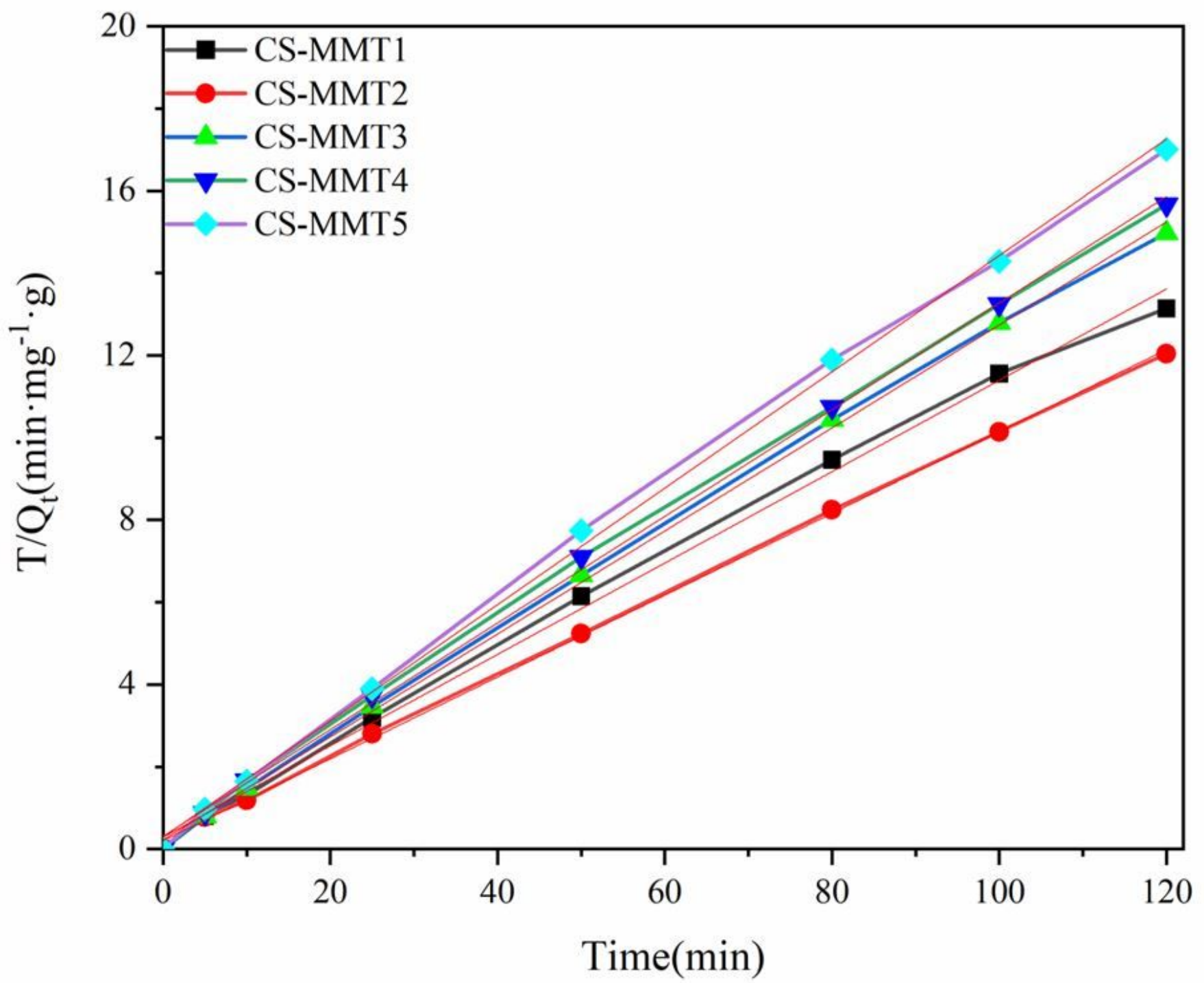

Figure 6

Pseudo-second-order model for adsorption of Cu2+ on CS-MMT composite aerogels 


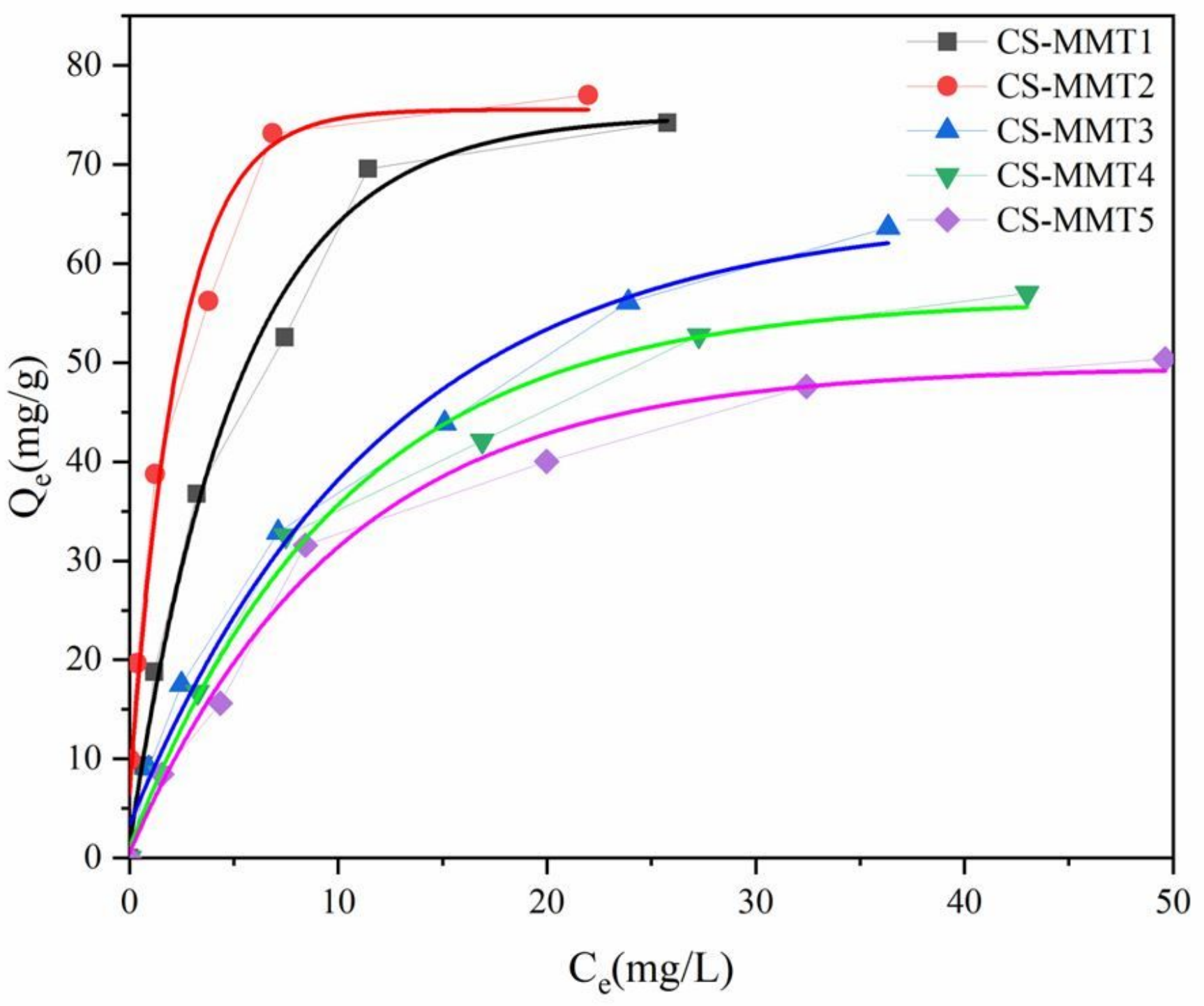

Figure 7

Adsorption capacity of CS-MMT composite aerogels for Cu2+ in different initial solution concentration 


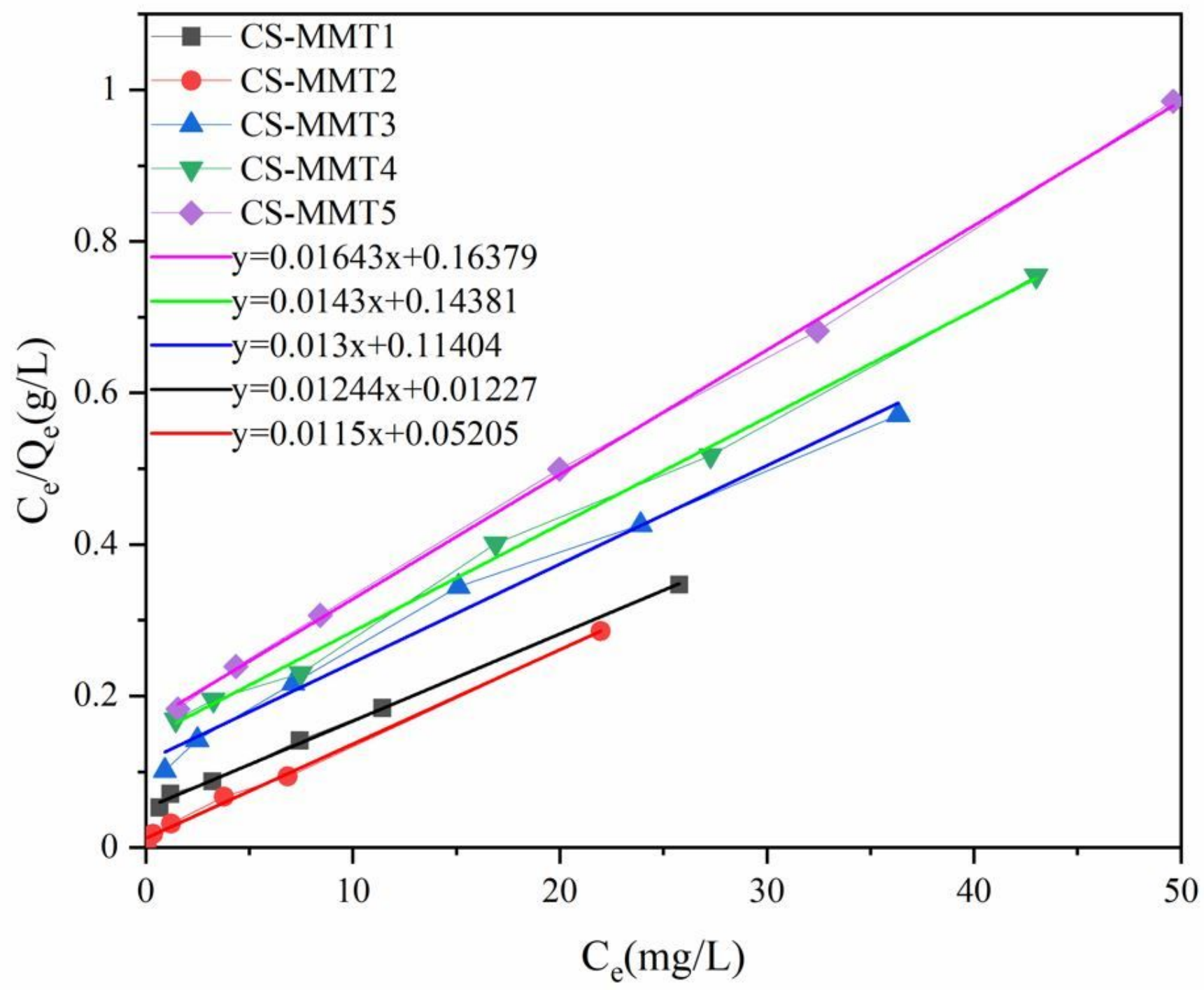

Figure 8

Langmuir isotherms plots of Cu2+ adsorption on CS-MMTs 


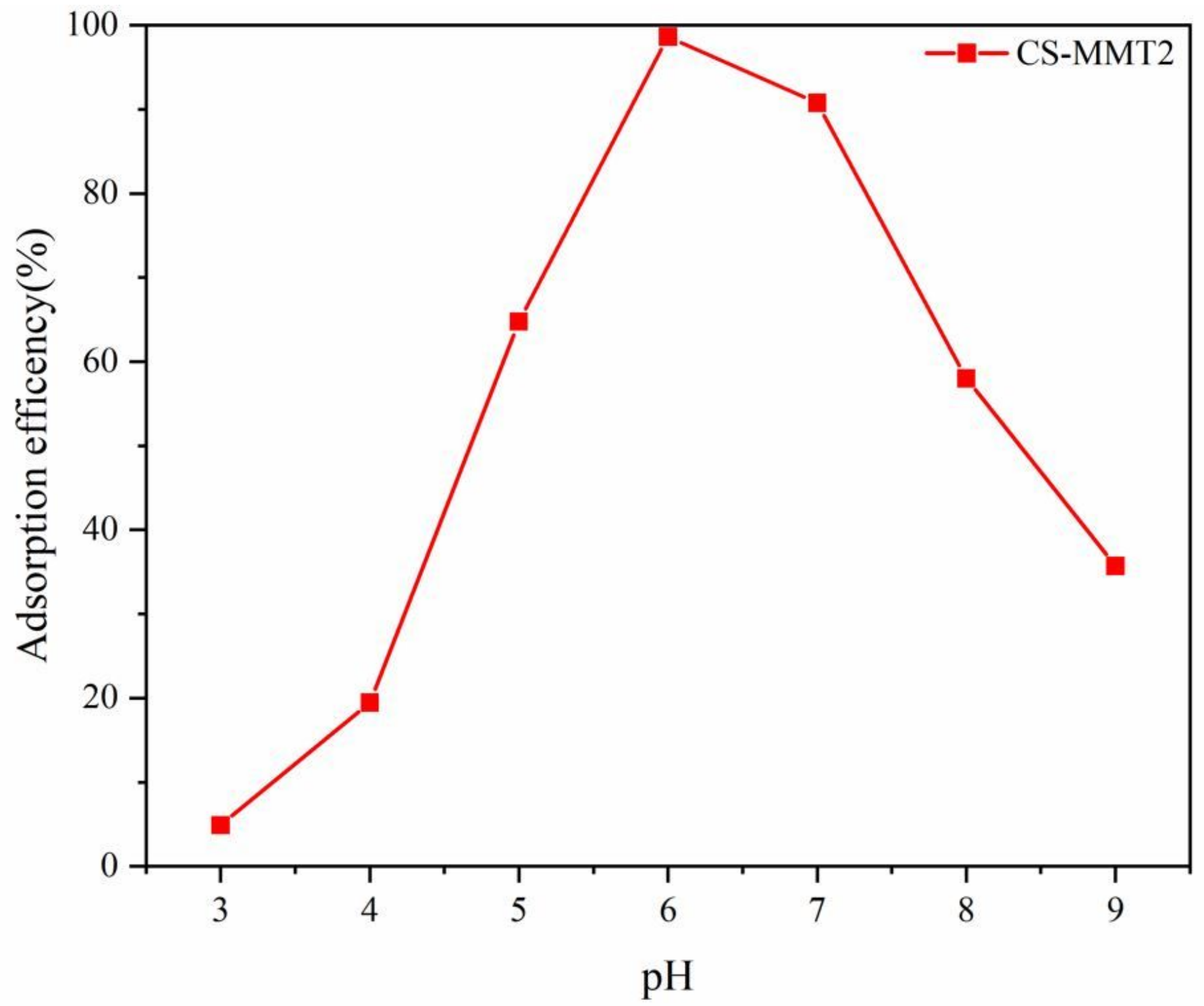

Figure 9

The effect of solution $\mathrm{pH}$ value on the adsorption capacity of Cu2+ by CS-MMT2 


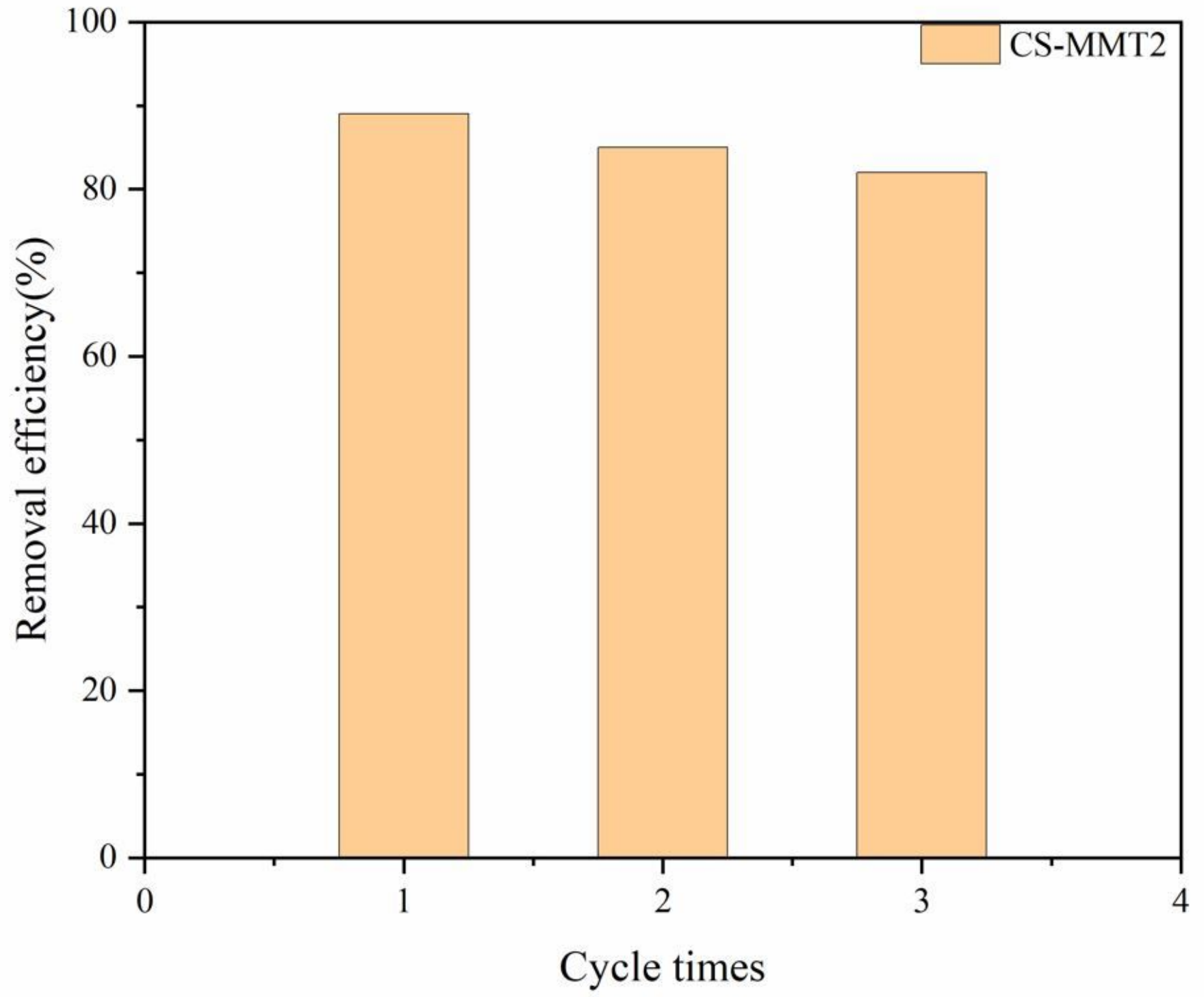

Figure 10

Circulation capability of CS-MMT2
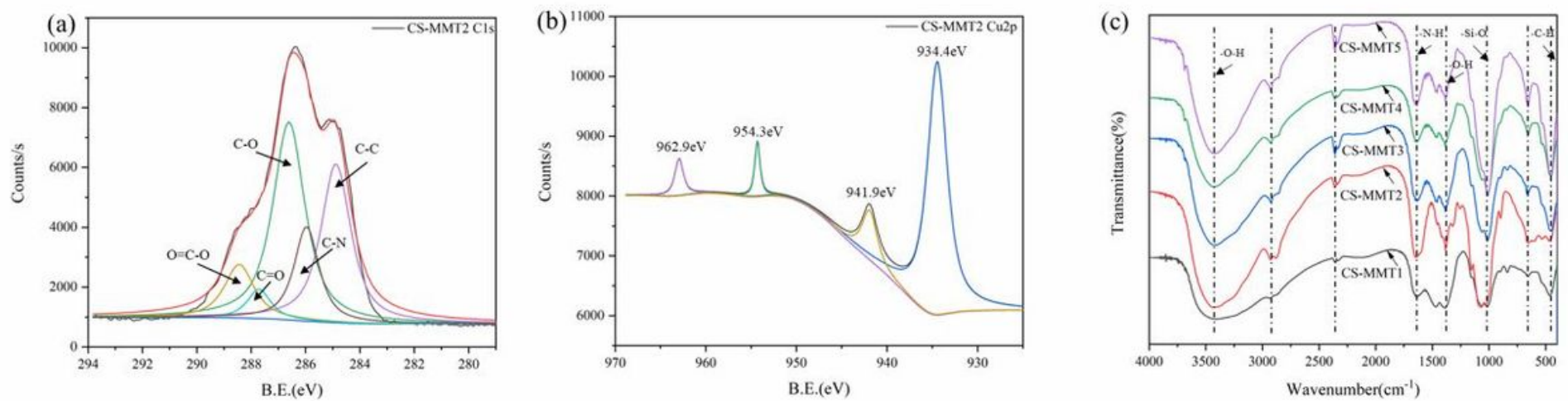

Figure 11 
(a) C1s, (b)Cu2p spin-orbit peaks of CS-MMT2 after adsorption, (c) FT-IR spectra of CS-MMTs after adsorption

\section{Supplementary Files}

This is a list of supplementary files associated with this preprint. Click to download.

- Sl.docx 